\title{
La constitucionalización de la integración regional europea. ¡Más Europa!: de vuelta a una constitución para Europa, ante la situación de crisis de la Unión
}

\author{
Juan Francisco Sánchez Barrilao \\ Profesor Titular de Derecho Constitucional \\ Universidad de Granada
}

Recibido: 01.10.2012

Aceptado: 15.10.2012

Resumen: A pesar de los indudables avances en la integración europea, incluso la consolidación de unas «tradiciones constitucionales comunes», la UE no ha sido capaz de crear una unión financiera y específicamente europea. En este artículo se argumentará que la solución pasa por otorgar una mayor flexibilidad frente a este panorama económico desfavorable para poder recuperar parte del poder perdido y reintegrarlo en el espacio público y democrático europeo, a la espera de que se den los presupuestos clásicos para una Constitución en Europa.

Palabras clave: constitucionalización de la UE, integración europea, unión financiera.

Abstract: Despite the great progress within the European integration, even the consolidation of the so-called common constitutional tradicions, the EU has been unwilling to create a true and specifically European Financial Union. This paper will argue that the solution will require a higher degree of flexibility to face the economic situation and recover a bit of the lost power in order to reintegrate in within the European public and democratic space, until we wait for the conditions for a true European Constitution. Union.

Key words: EU constitutionalization, European integration, Financial

Sumario: 1. Introducción: sobre la globalización y la crisis en Europa.-1.1. La globalización.-1.2. Una crisis económica, política, social y de valores en Europa.-2. El proceso de constitucionalización de la Unión Europea.-2.1. Preliminares y orígenes; consolidación y crisis. 2.2.-Momento actual, urgencia y cuestiones abiertas.-3. ¿Qué es lo que ha pasado para que la constitucionalización de la integración regional europea no haya avanzado al ritmo de la globalización? - 4. Consideraciones finales: qué hacer; de vuelta a la Constitución europea. 


\section{INTRODUCCIÓN: SOBRE LA GLOBALIZACIÓN Y LA CRISIS EN EUROPA $^{1}$}

Si durante años el proceso de integración europea ha sido contemplado, desde el Derecho comparado, como modelo regional de respuesta constitucional ante la progresiva pérdida de capacidad de los Estados frente a la globalización ${ }^{2}$, hoy en día, sin embargo, cabe reconsiderarse tal apreciación, a la vista de la grave situación en la que se encuentra la Unión Europea3: la imagen de una Unión protectora de sus ciudadanos ante la globalización ${ }^{4}$, parece desvanecerse como consecuencia de la crisis y la incapacidad demostrada por ésta y los Estados para salir de la misma. Es así que la llamada a jmás Europa! vuelva a recorrer la Unión, como respuesta a dicha crisis, y ante el riesgo abierto de su ruptura.

Ahora bien, tal apelación, entendemos, se ha de acompañar con la reflexión sobre qué Europa queremos (unos y otros), necesitamos (todos) y podemos lograr (finalmente). Y a tales efectos, que estimemos oportuno replantearnos el grado de constitucionalización que de la integración regional europea se ha alcanzado, a fin de no permanecer en un halo de mitificación de la misma; una mitificación que, lejos de hacer progresar entonces a la Unión Europea en su integración, acabase por debilitarla todavía más; y una debilitación que, a su vez, terminaría por perjudicar a los propios Estados que la conforman, como a los mismos ciudadanos (tanto en su condición de europeos y de nacionales) dado que sujetos y destinarios últimos del poder.

Para tal apreciación crítica del grado de integración alcanzado en Europa (y del que se pretenda, en su caso), y en cuanto que proceso de constitucio-

${ }^{1}$ El presente trabajo se ha realizado en el marco del Proyecto de Investigación «Los derechos fundamentales en el contexto de un mercado único» (DER2010-19863). Desde aquí, también, mi agradecimiento a M. AzPITARTE SÁNCHEZ y a E. GuILLÉn LóPEZ por sus intensos comentarios a estas páginas.

${ }^{2}$ Así, la Unión Europea como referencia constitucional con la que alcanzar, si bien a nivel regional, una masa crítica económica, social, política y jurídica suficientemente plausible como para afrontar los envites de la globalización, superando los tradicionales modelos tanto estatales, como internacionalistas. Por ejemplo, vid. Pizzorusso, A. «La producción normativa en tiempos de globalización», Aguilar CALAHORRO, A. (trad.), Revista de Derecho Constitucional Europeo, núm. 11, 2009, p. 241; o WiEnER, A. F. LANG Jr., Tully, J., M. Poiares Maduro, M. y Kumm, M., «Editorial. Global constitutionalism: Human rights, democracy and the rule of law», Global Constitutionalism, núm. 1, 2012, p. 5.

${ }^{3}$ Sobre la crisis europea, vid. MenÉndeZ, A. J., De la crisis económica a la crisis constitucional de la Unión Europea, Eolas Ediciones, León, 2012.

${ }^{4}$ Incluso de marca cabría hablar, más allá de mera imagen, por cuanto que está por ver hasta qué punto es responsabilidad de Europa, antes ya de la crisis, el progresivo debilitamiento del Estado social, dada la lógica esencialmente economicista de la misma; en tal sentido, DE CABo MarTín, C. Dialéctica del sujeto, dialéctica de la Constitución, Trotta, Madrid, 2010, pp. 106 y ss. 
nalización regional, entendemos necesario, a su vez, re-contextualizarla: y esto, de un lado, ante la específica realidad jurídico-política de la integración europea, formalmente no configurada como constitucional (de acuerdo a los cánones que han caracterizado la Constitución normativa $)^{5}$, sin perjuicio de reconocer, en su seno, elementos propios del Derecho constitucional que han ido progresando a lo largo del tiempo ${ }^{6}$, a la par que nuevas evoluciones del mismo $^{7}$; y de otro, ante la consideración abstracta de como el Derecho constitucional no cabe ser adecuadamente comprendido si no se enmarca en la realidad histórica en el que éste se desarrolla y encuentra ${ }^{8}$. En este sentido, la constitucionalización de Europa entronca en el tiempo con los procesos de cambios que viene suponiendo la globalización y su afectación a los sistemas constitucionales, además de con la concreta crisis económica, pero también política, social y de valores en la que se haya Europa; no en vano, el término «constitucionalización» que encabeza este ensayo hace referencia tanto a un proceso en desarrollo (dinámico), como ultimado (resultado y/o meta) .

Una aproximación a ambos contextos, por tanto, nos permitirá entonces revisitar luego, eso sí, viejas respuestas que se vienen planteando en torno a la constitucionalización de la integración regional europea, aunque desde nuevas perspectivas ahora ${ }^{10}$. Tal vez, finalmente, no sean respuestas originales las que

${ }^{5}$ Entre otros: KäGI, W. La constitucionalización como ordenamiento jurídico fundamental del Estado, Díaz Ricci, S. y Reyven, J. J. (trad.), Dykinson, Madrid, 2005; o Hesse, K. «Concepto y cualidad de la Constitución», Cruz Villalón, P. (trad.), en Escritos de Derecho Constitucional, Fundación Coloquio Jurídico Europeo/Centro de Estudios Políticos y Constitucionales, Madrid, 2011, pp. 33 y ss. Ya en España, y desde esta percepción, GARrorena Morales, A. Derecho constitucional (Teoría de la Constitución y sistema de fuentes), Centro de Estudios Políticos y Constitucionales, Madrid, 2011.

${ }^{6}$ Así, el concepto de «Constitución mixto» que plantea HäBERLE, P. al tiempo, por ejemplo en «¿Tiene España y Europa una Constitución?», AzPITARTE SÁnchez, M. (trad.), Revista de Derecho Constitucional Europeo, núm. 12, 2009, pp. 357 y ss.

${ }^{7}$ Como es la «teoría de la interconstitucionalidad» de Gomes CANotilho, J. J. en Teoría de la Constitución, LEMA AÑón, C. (trad.), Instituto de Derechos Humanos «Bartolomé de las Casas»/Dykinson, Madrid, 2003.

${ }^{8}$ Nuevamente Garrorena Morales, A. pero ahora en su ya clásico «Cuatro tesis y un corolario sobre el Derecho Constitucional», Revista Española de Derecho Constitucional, núm. 51, 1997, pp. 45 y ss.

${ }^{9}$ De ahí, consecuentemente, la conveniencia del estudio de la constitucionalización regional europea desde una perspectiva diacrónica, como sincrónica.

${ }^{10}$ No es lo mismo hablar de constitucionalización de la integración regional europea a comienzos del Siglo XXI, que ya en el 2012, a tenor de los retos que en uno y en otro momento se suscitan; y de este modo, el que respuestas ofrecidas en relación a la integración europea y la globalización en un período desde el Derecho constitucional, resulten sobrepasadas al tiempo a la vista del progreso que de la globalización se advierte, así como desde la crisis en la que se encuentra hoy Europa. Para una primera revisión del tema propuesto, a lo largo de una década, vid. SÁnchez BARrilao J. F.: «Globalización versus Democracia», Anales de la Cátedra Francisco Suárez, núm. 36, 2002, pp. 383 y ss.; «Globalizzazione, tecnología e Costituzione: verso una Democracia planetaria e un Diritto 
alcancemos. Y es que no es nuestro propósito buscar la originalidad sin más, pues de lo que se trata es de reflexionar de manera crítica sobre problemas que evolucionan y requieren, consecuentemente, de repuestas replanteadas a tenor del momento actual a fin de evitar que esas mismas respuestas (u otras), en sus planteamientos originarios, permanezcan entonces como meros mitos yertos ${ }^{11}$; reflexionar de esta forma críticamente sobre la constitucionalización de Europa en tanto que, y en palabras de LÓPEZ PINA, «proyecto irrenunciable» ${ }^{12}$.

Entremos de este modo, aún someramente, en ambos contextos.

\subsection{La globalización}

En cuanto a lo primero, la globalización se presenta como un proceso progresivo de difuminación de fronteras ${ }^{13}$, caracterizado, a su vez, por diver-

costituzionale comune?», BuRATTI, A. (trad.), Nomos-Le attualità nel diritto, núm. 3, 2002, pp. 169 y ss.; «Sobre la Constitución normativa y la globalización», Revista de la Facultad de Derecho de la Universidad de Granada, núm. 7, 2004, pp. 241 y ss.; «Relación entre el Derecho de la Unión Europea y el Derecho de los Estados miembros: apuntes para una aproximación al principio de primacía a la luz de la Constitución europea (Declaración del Tribunal Constitucional de 13 de diciembre de 2004)», Revista de Derecho Constitucional Europeo, núm. 2, 2004, pp. 127 y ss.; «Derecho europeo y globalización: mitos y retos en la construcción del Derecho Constitucional Europeo», Revista de Derecho Constitucional Europeo, núm. 12, 2009, pp. 115 y ss.; «Globalización y crisis económica: sombras en la integración europea», Vídetur quod. Anuario del Pensamiento crítico, 2010, pp. 184 y ss., en http://www.liberlex.com/archivos/globalizacion_UE.pdf(3/2/2012); y «Constitución, Derecho constitucional y globalización», 2012 (en prensa). A la vista de tales trabajos previos se advierte la falta de originalidad de buena parte de las ideas que se presentan en estas páginas, por cuanto que deudoras de aquéllos, sin perjuicio, eso sí, de su reconstrucción a la sombra, ahora, de las nuevas realidades en el que este discurso de desarrolla.

${ }^{11}$ Desde tal perspectiva, BALAGUER CALLEJón, F. «Derecho constitucional y Estado en un mundo globalizado», Conferencia impartida el día 24 de enero de 2011, dentro de los actos de la Festividad del Patrón de la Facultad de Derecho de la Universidad de Granada, Facultad de Derecho, Granada, 2011. No en vano, cualquier respuesta que se ofrezca al binomio Derecho constitucional-globalización ha de partir de los postulados que aún hoy caracterizan al Derecho constitucional, en tanto que conquistas históricas (por todos, HÄBERLE, P. Libertad, igualdad, fraternidad. 1789 como historia, actualidad y futuro del Estado constitucional, I. Gutiérrez Gutiérrez -trad.-, Trotta, Madrid, 1998), sin perjuicio de reconocer su necesaria adaptación a los tiempos vigentes (así, por ejemplo, AZPITARTE SÁNCHEZ, M. «La función de la Constitución en el contexto contemporáneo», Revista de Derecho Constitucional Europeo, núm. 12, 2009, pp. 171 y ss.). Por último, quisiéramos advertir de un constante feedback en el planteamiento y desarrollo de este trabajo, al recurrir a reenvíos temporales que, sin bien pueden en determinados momentos entorpecer una visión/lectura lineal del tema, buscan una mejor interrelación y comprensión del pasado, presente y posible futuro de la constitucionalización regional europea.

${ }^{12}$ LÓPEZ PINA, A. Europa, un proyecto irrenunciable (La Constitución para Europa desde la teoría constitucional), Dykinson, Madrid, 2004.

${ }^{13}$ Con carácter general sobre la globalización y sus efectos, y desde distintas aproximaciones a la misma, vid., por ejemplo: BECK, U. ¿Qué es la globalización? (Falacias del globalismo, respuestas a la globalización), Borràs, R. Ma y Moreno, B. (trad.), Paidós, 
sos factores y aspectos. Respecto a los factores, son dos a tener en cuenta: de una parte, el progreso tecnológico, como motor de la globalización, y en una aceleración tal que la diferencia de situaciones pasadas de cambios (a la par que globalización y desarrollo tecnológico acaban retroalimentándose) ${ }^{14} ; \mathrm{y}$ de otra, y en estrecha conexión con lo anterior, la sociedad del riesgo en la que vivimos, tanto a nivel medioambiental, como en cuanto a salud pública, economía o la misma forma de desarrollarse los conflictos y la violencia ${ }^{15}$.

Por otro lado, y respecto a los aspectos que caracterizan la globalización, está, primeramente, su condición compleja y contradictoria, pues: junto a la proyección universalista de la economía, de valores sociales y políticos, de manifestaciones culturales, e incluso del propio Derecho, se presentan respuestas endógenas frente a la misma, siendo el integrismo (nacional, religioso, cultural, etc.) su mayor demostración ${ }^{16}$; y en cuanto a las contradicciones que supone la globalización, lejos de que ésta haya dado lugar a una mayor universalidad respecto a las más importantes conquistas históricas alcanzadas ${ }^{17}$, ha provocado una mayor brecha y desigualdad internacional en todos los órdenes (económico, cultural, social, tecnológico, etc.) ${ }^{18}$. Con ello, además, está

Barcelona, 1998; Faria, J. E. El Derecho en la economía globalizada, Lema Añón, C. (trad.), Trotta, Madrid, 2001; BALDASSARRE, A. Globalizzazione contro democracia, Editori Laterza, Bari, 2002; DenNINGER, E. «Derecho en 'desorden' global. Sobre los efectos de la globalización», Brage Camazano, J. (trad.), Anuario Iberoamericano de Justicia Constitucional, núm. 8, 2004, pp. 117 y ss.; Von Bogdandy, A. «Globalization and Europe: How to Square Democracy, Globalization, and International Law», The European Journal of International Law, núm. 15/5, 2004, pp. 885 y ss.; y CAPELLA, J. R. «La globalización: ante una encrucijada político-jurídica», Anales de la Cátedra Francisco Suárez, núm. 39, 2005, monográfico sobre Derecho y justicia en una sociedad global, pp. 13 y ss.

${ }^{14}$ En cuanto al desarrollo tecnológico imperante y su incidencia en el Derecho constitucional, vid., ya, SÁNCHEZ BARRILAO, J. F «Sobre la Constitución normativa y la tecnología», Revista de la Facultad de Derecho de la Universidad de Granada, núm. 8, 2005, pp. 257 y ss. Y además, sobre la incidencia de la ciencia y la tecnología, en general, vid. ESTEVE PARDo, J., El desconcierto del Leviatán (Política y Derecho ante las incertidumbres de la Ciencia), Marcial Pons, Madrid, 2009.

${ }^{15}$ Por todos, Beck, U., La sociedad del riesgo (Hacia una nueva modernidad), NAVArro, J.; JiMÉnez, D. y BorRÁs, Ma R. (trad.), Paidós, Barcelona, 1998.

${ }^{16}$ En cuanto al carácter complejo de la globalización, cfr. GIDDENS, A. Un mundo desbocado, Cifuentes, P. (trad.), Taurus, Madrid, 2000; y sobre el fundamentalismo, como grave problema del Derecho constitucional, ya HÄBERLE, P., «El fundamentalismo como desafío del Estado constitucional: consideraciones desde la ciencia del Derecho y de la cultura», Arzoz Santiesteban, X. (trad.), en Retos actuales del Estado constitucional, Instituto Vasco de Administración Pública, Oñati, 1996, pp. 133 y ss.

${ }^{17}$ Spantigati, F., «Globalizzazione e decumene: cosa abbiamo imparato in Italia in cinquanta anni», Jus-Rivista di Scienze Giuridiche-, 1/2001, pp. 15 y ss.

${ }^{18}$ En tal sentido, por ejemplo, HernÁndeZ ZubizArReTA, J., Las empresas transnacionales frente a los derechos humanos: historia de una asimetría normativa (De la responsabilidad social corporativa a las redes contrahegemónicas transnacionales), Hegoa/OMAL, Bilbao, 2009. Al respecto, tampoco cabe hablar de una globalización del 
la intensidad con la que la globalización actúa, al suponer cierta capitulación democrática y constituciona $1{ }^{19}$ en relación al modelo constitucional de Estado de Derecho y de Democracia históricamente alcanzado ${ }^{20}$ : en tal sentido, precisamente, el determinismo que para la política y lo público supone hoy el mercado globalizado, ante la negación de la política como voluntad con capacidad externa al mismo (como lo evidencia la actual crisis económico-financiera, según se viene a mostrar más adelante) ${ }^{21}$. Es de este modo que resulte pacífico considerar como la acción de la globalización ha reducido buena parte de la efectiva capacidad de los Estados para decidir e intervenir en esferas de actividad tradicionalmente públicas (tanto dentro, como fuera de sus fronteras), dejando al ciudadano en la intemperie globalizada ${ }^{22}$.

Derecho, en sentido estricto (y más allá de ciertas manifestaciones -como los derechos humanos-, por cuanto que, aún expandiéndose, finalmente no acaban por universalizarse totalmente), sino de cómo queda éste bajo el influjo de aquélla: así, Derecho globalizado. Por todos, CASSESE S. : «The Globalization of Law», International Law and Politics, núm. 37, 2005, pp. 973 y ss.; e Il diritto globale (Giustizia e democracia oltre lo stato), Einaudi, Torino, 2009.

${ }^{19}$ Así, Ferrara, G., «Costituzione e revisione costituzionale nell'età della mondializzazione» en AAVV Scritti in onore di Giuseppe Guarino (II), CEDAM, Padova, 1998, pp. 228 y 229; y ya en España, especialmente, JÁurEguI, G., La Democracia planetaria, Ediciones Nóbel, Oviedo, 2000, pp. 20 a 23.

${ }^{20}$ Sobre tal modelo, y su crisis, vid., entre otros: GrIMN, D., «Il futuro della costituzione», FIORE, F. (trad. it.), en AAVV Il futuro della costituzione, ZAGREBELSKY, G.; PORTinARO, P. P. Y LUTHER, J. (coord.), Einaudi, Torino, 1996, pp. 129 y ss.; o DE CABO MARTín, C. «Constitucionalismo del Estado social y Unión Europea en el contexto globalizador», Revista de Derecho Constitucional Europeo, núm. 11, 2009, pp. 17 y ss.

${ }^{21}$ En tal sentido, SEVERINo habla de cómo el capitalismo ha llevado a la desregulación, a tenor del distanciamiento del mercado de todo fin ajeno al mismo y en cuanto que capaz de limitarlo en su desarrollo; EsEverino, E. junto a IRTI, N., Dialogo su Diritto e tecnica, Editori Laterza, Roma, 2001, pp. 26 y 70. La economía, así, y en tanto que supuestamente dada y objetiva, se presenta como límite frente al Derecho y la voluntad político-pública (democrática), subyugándolos en pos de unas reglas propias basadas en el máximo beneficio de quienes participan a título particular en el mercado globalizado (sin embargo el Derecho no desaparece: de un lado, y como advirtiera nuevamente SEVERINO, E. en cuanto que necesario marco garante de las pretensiones de aquéllos-op. cit., pp. 70 a 72). Tal determinismo se nos muestra, desde hace tiempo, con un solapado valor político, al rechazar la política por negativa y acientífica; no es que se haya negado la política a nivel público, pues lo que se ha pretendido (y se sigue pretendiendo) es que ésta sea sustituida por una voluntad aparentemente apolítica (parapolitica) garante de una parca objetividad, al margen, en última instancia, del principio democrático, e intentándose volver de esta forma al Estado de Derecho privado (JÁUREGUI, G. op. cit., pp. 48 a 54; de «constitucionalismo mercantil global», incluso, habla DE JulIOS-CAMPUZANO, A. en La globalización ilustrada -Ciudadanía, derechos humanos y constitucionalismo-, Dykinson, Madrid, 2003, p. 129).

${ }^{22}$ ¿Qué contradicción!, es cuando el Estado alcanza históricamente su mayor proyección democrática y garantista respecto a los individuos cuando comienza a vislumbrarse su impotencia; cfr. DE Vega GarcíA, P. «Mundialización y Derecho constitucional: la crisis del principio democrático en el constitucionalismo actual», Revista de Estudios Políticos, núm. 100, 1998 , pp. 14 y 29. 
No obstante, advertido el impacto de la globalización en los Estados constitucionales y en los sistemas jurídicos y políticos en ellos vigentes, no resulta en cambio tan pacífico las posibles respuestas al respecto, dada las complejas y contradictorias consecuencias que de la globalización se aprecian a nivel mundial. De este modo, cabe señalar desde el influjo constitucional y democrático en las recientes revoluciones en el mundo árabe (primavera de 2011), como en la contestación indignada de los ciudadanos ahora en no pocas democracias occidentales reclamando, precisamente, mayor participación política (asimismo, desde primavera de 2011); pero también, y de manera opuesta (además del estancamiento de tales procesos democráticos), el asentamiento en Estados democráticos de gobiernos tecnócratas (Grecia e Italia, 2011). Si de expansión del Derecho constitucional cabe hablar en relación a lo primero, de limitación y crisis de la Constitución cabría hablar respeto a lo segundo. Ello no es sino consecuencia del carácter contradictorio y complejo de la globalización (más arriba referido), que, de un lado, es capaz de irradiar a nivel mundial valores humanos y democráticos, a la par que atenaza los procesos políticos a la razón económica; de otro, potencia la mundialización cultural, mientras que, y sin embargo, acaba colonizando la cultura al servicio del mercado global; genera sentimientos cosmopolitas, para finalmente advertir respuestas endogámicas frente «al otro»; da lugar a una mayor riqueza para unos, cuando cada vez hay más con menos.

Lo que sí cabe apreciar, con todo, es una doble constante. Una, el progreso del Derecho constitucional tanto a nivel mundial, como regional, yendo más allá de los Estados; y esto, a la vista de cómo componentes característicos del Derecho constitucional acaban institucionalizándose en instrumentos jurídicos internacionales, como en otros de carácter más local. Y como segunda constante, el debilitamiento, y aun paradójicamente, de las propias Constituciones normativas, en cuanto que incapaces de ordenar, de manera efectiva, el ejercicio del poder en el seno de los Estados. El Derecho constitucional, aun limitando el ejercicio del poder, viene mostrándose más flexible y adaptable que las Constituciones normativas, en sentido estricto, lo que en principio, nuevamente, respondería mejor a la coyuntura cambiante generada por la globalización; y es que la normatividad constitucional, en estrecha relación con la rigidez constitucional, no resulta aparentemente tal eficiente ante dicha realidad cambiante. Sin embargo el Derecho constitucional comienza a mostrar, finalmente, el efecto perverso de catalizar el debilitamiento de la normatividad constitucional, y con ello (al tiempo) la capacidad misma y efectiva de limitar y ordenar el poder (lo que inicialmente, por otra parte, dicho Derecho pretende) ${ }^{23}$. Es cierto que tal situación ha generado, en el caso de los Estado europeos, una cierta capacidad para actuar bordeando sus respectivas

${ }^{23} \mathrm{Al}$ respecto del Derecho constitucional y la limitación del poder, por todos, MATTEUCCI, N., Organización del poder y libertad (Historia del constitucionalismo moderno), Ansuategui Roig, F. J. y Martínez Neira, M. (trad.), Trotta, Madrid, 1998. 
Constituciones en relación al espacio europeo (como más adelante se señalará); pero ello no está tan claro al día de hoy, al encontrarse ya buena parte de éstos bajo un protectorado difuso europeo, a la par que sometidos a una permanente tormenta financiera (Grecia, Irlanda, Portugal y España, pero también Italia). Y cierto es, asimismo, que el poder público está cada vez más limitado, mas ya no está tan claro que ello sea al servicio de los ciudadanos y las personas.

Ahora bien, siendo dinámico el anterior contexto presentado, en cuanto que globalización como proceso, resulta también oportuno, en un paso más, plantear (aun muy someramente, nuevamente) cómo se ha desenvuelto la integración europea en relación a la globalización, y al hilo de ello, claro está, la constitucionalización de la Unión Europea hasta llegar a nuestros días (a ello dedicaremos el segundo epígrafe $)^{24}$; pero antes, detengámonos en la crisis que vive Europa (tal como habíamos adelantado).

\subsection{Una crisis económica, política, social y de valores en Europa}

En cuanto a la crisis económica, que aún mantiene estancada (y en vilo!) a Europa, se vienen indicando diversas causas en su origen: desde la más genérica conjunción de la globalización económica con la desregularización que del mercado financiero internacional se advierte desde finales del siglo pasado; a otras más concretas, referidas ahora al exceso de riesgo especulativo en el mercado financiero, junto con la explosión de la burbuja inmobiliaria en el sur de los Estados Unidos, y que terminó por colapsar grupos bancarios y aseguradoras a nivel mundial. Ello, a su vez, ha tenido diversas repercusiones a nivel estatal, según circunstancias específicas de sus respectivas economías, como precisamente acontece en España en razón, asimismo, a la caída del sector inmobiliario, dado que principal motor económico en tal momento 25 .

Por otra parte, dicha crisis, que se inicia en 2007, ha sufrido distintas evoluciones que, sin perjuicio de mantenerla viva, responden a las diversas medidas económico-estatales adoptadas al respecto, así como a las referidas circunstancias de las economías estatales; y en este sentido, y en relación a

${ }^{24}$ Para una preliminar aproximación al progreso de la integración Europea, desde el Derecho constitucional europeo, vid.: CÁMARA VILLAR, G., «Perfiles históricos del Derecho constitucional europeo», Revista de Derecho Constitucional Europeo, núm. 11, 2009, pp. 209 y ss.; y BALAgUer CALLEJÓn, F., «El Derecho constitucional europeo y la Unión Europea», junto a Cámara Villar, G. Balaguer Callejón, M. L. y Montilla Martos, J. A., en Introducción al Derecho constitucional, F. Balaguer Callejón (coord.), Tecnos, Madrid, 2011, pp. 85 y ss.

${ }^{25} \mathrm{Al}$ respecto de la crisis económica, vid. Tugores Ques, J., Crisis: lecciones aprendidas... o no, Centro de Estudios Internacionales/Marcial Pons, Madrid, 2010. También de interés, para una lúcida aproximación al vigente capitalismo, vid. CHANG, H. J., 23 Things They Don't Tell You About Capitalism, Penguin Books, London, 2010. 
la Unión Europa, la específica crisis surgida en su seno en atención al excesivo endeudamiento público de algunos de sus Estados, en principio Grecia, y de las dificultades encontradas en su refinanciación a finales ya del 2009 (profundizada a comienzos del 2010), y extendiéndose a otros Estados como Irlanda y Portugal (2010 y 2011), o a España e Italia al tiempo (2011 y 2012$)^{26}$.

Pero siguiendo con la crisis económica en la Unión Europa, ésta, de un lado, vino a coincidir con la crisis política originada por el fracaso del Tratado constitucional, además de con el proceso de elaboración y la accidentada ratificación del Tratado de Lisboa ${ }^{27}$; pero también, con la falta de mecanismos tanto comunitarios, como de los propios Estados miembros, para afrontarla de manera efectiva ${ }^{28}$. Es de este modo que la Unión y los Estados miembros únicamente pudieran, inicialmente, coordinar sus políticas económicas, lo cual, ante el déficit de gobernabilidad política de la Unión Europea (y los conflictos surgidos entre los distintos Estados, a la hora de atajarla), requirió de bastante tiempo, dando así oxígeno a la crisis económica en Europa. Ciertamente, con todo, se consiguió adoptar medidas ${ }^{29}$, con las que, aun siendo discutidas, limitadas y $\operatorname{tardías}^{30}$, parecería nuevamente asumirse cómo la integración europea, ante situaciones de crisis, termina finalmente por pro-

${ }^{26}$ Las «PIGS»: Portugal, Irlanda, Grecia y España (Spain). Tal acrónimo es habitualmente utilizado por la prensa anglosajona para referirse a dichos países, en tanto que economías históricamente débiles y poco desarrolladas, a pesar del avance vivido en las mismas antes del inicio de la vigente crisis económica (lo que precisamente planteaba numerosas suspicacias al respecto, y finalmente materializadas con ocasión de la crisis); así, por ejemplo, VON REPPERT-BISMARCK, J. «Why Pigs Can’t Fly», en Newsweek Magazine, 28 de junio de 2008 (asimismo, en http://www.thedailybeast.com/newsweek/2008/06/28/why-pigs-can-t-fly.html -14/1/2012-). Y al tiempo, como «PIIGS», a fin de integrar también a Italia.

${ }^{27}$ De interés, MARTín J. y PÉREZ DE NANCLARES, «Sin Tratado de Lisboa y en un escenario de crisis financiera global: sobre la necesidad de buscar el tercer impulso al proceso de integración», Revista General de Derecho Europeo, núm. 17, 2008.

${ }^{28}$ En cuanto a esto último, la unión económica y monetaria que surgiría a la luz del Tratado de Ámsterdam se limitó a establecer mecanismos de política monetaria para los Estados miembros de la zona euro, mientras que la política económica quedaba compartida entre la Unión y los Estados, de acuerdo al reparto de competencias entre ésta y ellos; y así, una capacidad limitada de unos y otros con relación a la gobernanza económica europea y estatal, por cuanto que ni la Unión, ni los Estados, gozan de plena capacidad al respecto.

${ }^{29}$ Destacando, en particular, la creación en mayo de 2010 de un «fondo de rescate» cofinanciado con aportes de los Estados miembros de la eurozona y del Fondo Monetario Internacional; fondo, por otra parte, al que finalmente se ha dado carácter de permanencia mediante una reforma parcial del Tratado de Lisboa, tal como fuera acordado en el Consejo Europeo, de 28 y 29 de octubre de 2010 (mas sin modificar el principio de «no corresponsabilidad financiera»), además de la previsión de un mayor control del endeudamiento público de los Estados por parte de la Unión Europea.

${ }^{30}$ PÉrez CARrillo, E. F., «Crisis económica y financiera en la Unión Europea. Reflexiones en torno a algunos instrumentos estratégicos para la recuperación», Anuario Mexicano de Derecho Internacional, núm. XI, 2011, pp. 487 y ss. 
gresar y salir adelante ${ }^{31}$; pero con ello, también, asumiéndose el permanente estadio de sombras que vive la integración europea con ocasión de graves crisis, pues acaba emergiendo el referido pluralismo y conflicto subyacente en Europa, si bien suponiéndose luces dada la forma en la que (hasta ahora) ésta ha terminado por salir del túnel.

Sin embargo en esta ocasión no es sólo que el túnel esté resultando más largo de lo deseado y previsto inicialmente (pues las luces aun quedan lejos... ), sino que el coste político y social de la travesía europea en la crisis económica está debilitando muy gravemente la integración de Europa. Y ello en base no sólo a la limitada capacidad que la Unión Europea ha demostrado para responder a la crisis (al día de hoy, insistimos), sino en relación, especialmente, a la actuación de los Estados desarrollada tanto en su seno y conjuntamente, como a nivel individual, y a la percepción que la ciudadanía está alcanzando de este proceso. De lo que se trata, por tanto, no es sólo del déficit económico en el que puede quedar Europa tras salir de la crisis respecto a su coste económico y al lugar en el que se sitúe en el ranquin del mercado global; la cuestión más importante, considero, es el coste político y social de una Europa que, en una situación de grave crisis económica ha resultado (hasta ahora) incapaz de aprovechar la situación para relanzar su integración política, mostrándose en cambio débil y dividida, además de en retroceso a nivel social. A buen seguro, ello está ya reduciendo el apoyo ciudadano al desarrollo de la integración en el futuro, siendo éste esencial como se ha demostrado tanto en el fracaso del Tratado constitucional, como en la ratificación del de Lisboa ${ }^{32}$.

${ }^{31}$ Siguiendo a HABERMAS, cabría incluso hablar de un nuevo paradigma en relación a la gobernanza económica y a la integración europea; HABERMAS, J. «En el euro se decide el destino de la UE», Alborés Rey, J. (trad.), El País, 23 de mayo de 2010.

${ }^{32}$ Pero veamos con mayor detalle algunas de tales cuestiones. En relación a la propia Unión Europea, e inicialmente, está la incapacidad demostrada, junto con el resto de potencias económicas mundiales, de poner coto jurídico al neoliberalismo financiero y especulativo que originó la crisis. Cierto que ello se plantea en un contexto mundial, global, y por tanto desde una responsabilidad compartida tanto en relación a su incapacidad de respuesta, como de su propia previsión; pero no se ha de olvidar que, aun siendo los últimos responsables aquéllos que originaron la crisis, no es menos cierto que también, y en especial frente a la ciudadanía, son los poderes públicos los que mostraron, y aun siguen haciéndolo, dejación de sus tareas a la hora de encarar una nueva y adecuada regulación del mercado financiero internacional. Y centrándonos ahora a nivel interno de la Unión, los comienzos titubeantes y lentos al respecto de la crisis hacían ya presagiar cierta insuficiencia de ésta para enfrentarse adecuadamente a la misma; cierto es que, conforme se ha indicado, la Unión Europea como tal no tiene plena capacidad jurídica y política para haber adoptado las medidas que precisaba la crisis inicialmente, dado que compartidas con los Estados miembros. Cierto es, también, que incluso en materia monetaria, la capacidad europea se limita a la zona-euro. Pero al respecto de esto cabe recordar el retraso con que el Banco Central Europeo comenzó a bajar los tipos de interés ante el miedo al fantasma de la inflación y en atención a la sugestión de Alemania; y ello, incluso, frente a una Francia que reclamaba pública y contundentemente dicha bajada a fin de dar mayor 
$\mathrm{Y}$ en tal sentido, precisamente, el sentimiento de desapego manifestado recientemente en Grecia, tras las elecciones de mayo de 2012, en la que los partidos que vinieron gestionando la crisis hasta tal momento sufrieron una fuerte derrota, dando lugar a una situación de incapacidad política para formar gobierno y volviéndose a convocar nuevas elecciones para el 17 de junio (si bien, finalmente, con un gobierno de coalición entre Nueva Democracia y el Pasok, tras semanas de tensión política en toda Europa y con planes, incluso, para el caso de que Grecia hubiera de abandonar la zona euro tras dicho proceso electoral) $)^{33}$.

Y es que (y volviendo en el tiempo al primer rescate griego), en el origen de la crisis en Grecia (ocasionada por un endeudamiento excesivo, sin perjuicio de cierta artificiosidad de la misma, además de las deficiencias propias del sistema griego $)^{34}$ se expuso ya públicamente una grave falta de solidaridad inicial entre los Estados europeos ${ }^{35}$, a pesar del expreso reconocimiento de dicha solidaridad a nivel de la Unión (aun en diversas dicciones y esferas), conforme al Tratado de Funcionamiento de la Unión Europea (arts. 67.2, 80,

liquidez monetaria a su economía en aquel momento de búsqueda de confianza. Ya en este momento, y con tal supuesto, se evidencian así varias constantes en esta crisis: de un lado, el excesivo peso, aun justificado de los intereses de Alemania en la determinación común de las medidas a adoptar; de otro, el enfrentamiento, y el conflicto, entre distintos Estados y la propia Unión Europea a la hora de plantear las medidas a desarrollar; y por último, cómo a nivel interno los Estados de la zona euro ven particularmente limitada su capacidad para tomar decisiones por cuanto que sujetos a una integración monetaria en torno a una moneda única, el euro. De esta forma, la natural y preliminar salida a casi cualquier crisis económica de devaluar la moneda, o bajar, o subir, los tipos de interés, quedaba ya fuera del ámbito político de los Estados miembros de la euro-zona, y en manos de un Banco Central Europeo que, aun irresponsable políticamente ante los órganos políticos de la Unión Europea y sus Estados miembros, viene, no obstante, validando decisiones de unos Estados frente a otros.

${ }^{33}$ Y ello, además, tras la propuesta de Papandréu, a finales de octubre de $2011-31$ de octubre-, de someter a referéndum las medidas anticrisis relativas al segundo plan de rescate griego; el inmediato bloqueo por Francia y Alemania de la ayuda a Grecia (2 de noviembre), y la retirada por Papandréu de la propuesta de referéndum, negociando un gobierno de unidad -3 de noviembre-, y cediendo luego el poder (6 de noviembre); y el ulterior nombramiento de Papademos como Primer Ministro griego, dando lugar a un gobierno técnico en Grecia (10 de noviembre).

${ }^{34}$ Dado que en parte promovida por la especulación financiera; recuérdese la intervención, incluso, de los servicios secretos al respecto, y el símil de los especuladores financieros como «manadas de lobos» a la caza de una debilitada Grecia. Sobre ello, vid. AYALA, J. E., «El rescate de Grecia: la solidaridad europea se pone a prueba», Política Exterior, núm. 134, 2010, pp. 13 y ss.

${ }^{35}$ Siendo este principio jurídico esencial en la conformación constitucional tanto del propio sistema político (recuérdese su fundamentación revolucionaria en Francia, ante su defensa frente al resto de monarquías absolutas europeas), como de su articulación federal (tal como se teorizó al comienzo de la andadura federal norteamericana, a fin de justificar impuestos federales con los que sostener un ejército federal y permanente). 
122.1, 194.1, y 222.1 y 3) y al vigente Tratado de la Unión Europea (art. 3.3), especialmente. Por momentos Grecia, cuna de la cultura occidental, pareció dejada a su suerte por Europa: ¡qué ironía!; el mito griego de Europa traicionado por una Unión Europea abierta al debate sobre su identidad, pero reacia a darle sentido ${ }^{36}$. Las iniciales reticencias mostradas entonces en torno al rescate griego ${ }^{37}$ no presagiaban ya, precisamente, un buen camino en el que progresar en la integración europea y salir de la crisis; al contrario, mostraron una falta de solidaridad y de responsabilidad del todo necesaria, si no al menos para conformar un pueblo europeo, sí que, desde luego, para progresar en una Europa con diversos y distintos pueblos pero bajo un sentimiento de integración común.

Pero además de lo anterior, está el precio a pagar por los pueblos heleno, irlandés, portugués y español por sus respectivos rescates (en el caso de España, junio-julio de 2012) ${ }^{38}$, además del italiano, entre otros; un precio no sólo económico, sino social, en atención a los recortes sociales que conlleva y a la frustración de sentirse bajo un protectorado europeo y ante un Gobierno irresponsable ${ }^{39}$. Y es que la excusa europea, como la de la crisis global, está

${ }^{36}$ Por cierto, en las conclusiones del referido Consejo Europeo de 28 y 29 de octubre de 2010, y por tanto, tras un período de reflexión política desde el comienzo de la crisis griega, no se hizo mención alguna a tal principio, limitándose a buscar un reforzamiento de la gobernanza económica en Europa y de su pilar económico, además de buscar una mayor solidez en la gestión de la crisis.

${ }^{37}$ Las reticencias del gobierno alemán a dicho rescate en un primer momento, como ha criticado Habermas, J. («En el euro se decide el destino de la UE... cit.; asimismo, de interés, vid. GuÉROT, U., «El rapto de Europa: la crisis desde Alemania», Política Exterior, núm. 136, 2010, pp. 50 y ss.), como incluso el planteamiento, en aquel primer momento, a nivel interno de propuestas dirigidas a la salida voluntaria de Grecia del euro (como incluso del propio marco alemán), o de que vendiera parte de su patrimonio cultural!. Otra cosa es ya, al tiempo, el que se estuviera efectivamente especulando con un posible escenario de una definitiva salida griega del euro, a finales de mayo de 2012, ante la situación de bloqueo político y económico en la que Grecia se encontraba en tal momento (si bien desactivada más tarde, tras las elecciones de junio y la coalición de gobierno alcanzada), para luego volver a plantearse a finales de julio de 2012 nuevamente.

${ }^{38}$ Hablamos de rescate en relación a España, sin perjuicio de que inicialmente se pretendiera limitar su impacto político y social al presentarse como mera «línea de crédito a la banca» desde Europa (desde tal perspectiva, NúÑEZ, M., «Razones por las que no es un rescate», $A B C$, 11 de junio de 2012, en http://www.abc.es/20120611/economia/abcp-razones-rescate20120611.html-11/6/2012-). Sin embargo, de intervención habría de hablarse finalmente, a la vista del memorándum al tiempo remitido por la Unión al Gobierno español y las exigencias en él contempladas («Memorandum of Understanding on Financial-Sector Policy Conditionality», en http://ep00.epimg.net/descargables/2012/07/10/14540e59ee5504648623c 2bb5da8 08b8.pdf -12/07/2012-), sin perjuicio del planteamiento de un segundo rescate ya al Estado a finales de julio de 2012, a la vista de la prima de riesgo española y del muy elevado interés a pagar por España para su financiación.

${ }^{39}$ Con ello no nos referimos a la responsabilidad, en sentido fuerte, de adoptar medidas tendentes a resolver un problema (sin perjuicio de cuál sea nuestro juicio al respecto de 
provocando a su vez, a nivel interno de los Estados europeos, la coartada perfecta para desmantelar buena parte del Estado social. Al margen de los recortes sociales en los Estados con más problemas económicos (como sería el caso de Grecia, Irlanda, Portugal y España, pero también el de Italia), ciertamente existe la percepción de cómo la crisis económica está siendo utilizada para cambios en las políticas sociales en casi todos los Estados europeos, más allá de lo que la propia crisis exigiría razonablemente ${ }^{40}$. Ello, obviamente, acaba por no entenderse por buena parte de su ciudadanía, más cuando la crisis no termina por golpear de igual manera a todos ${ }^{41}$. El Estado social se tambalea asín ${ }^{42}$, además de presenciarse la poda de una de las ramas a partir de la cual construirse la referida identidad del árbol europeo, el Estado social, en cuanto que instrumento de corrección de las desigualdades y promoción del individuo, a la par que garantía de servicios hoy considerados básicos para las per-

las mismas), sino a: de un lado, la falta de responsabilidad en su sentido preventivo (tal como la definiera JoNAS, H. en El principio de responsabilidad: Ensayo de una ética para la civilización tecnológica, SÁnchez PASCUAL, A. -trad.--, 2. ' ed., Herder, Barcelona, 2004), ante el riesgo cierto y evidente de una crisis que no terminaba de enderezarse y un gasto público no contenido; y de otro lado, la falta de responsabilidad ante la recurrente excusa de la integración europea como causa de tales medidas (como desde hace tiempo viene denunciando BALAgUer CALLEJón, F. dado que respuesta fácil en el seno de los Estados europeos cuando tienen que justificar medidas no populares en el seno de los mismos, en "Los tribunales constitucionales en el proceso de integración europea», Revista de Derecho Constitucional Europeo, núm. 7, 2007, pp. 335 y ss.). Por último, sobre la responsabilidad como principio constitucional, y sus nuevos desarrollos, vid. Gomes CANOTILHO, J. J., «Principios y "nuevos constitucionalismos». El problema de los nuevos principios», M. Rodrigues CANOtilho (trad.), Revista de Derecho Constitucional Europeo, núm. 14, 2010, en especial pp. 334 y ss.

${ }^{40}$ Nuevamente Krugman, P. pero ahora iAcabad ya con esta crisis!, García, G. y Belza, C. (trad.), Crítica, Barcelona, 2012.

${ }^{41}$ Dado que, hasta ahora: de una parte, la banca resulta rescatada, sin paritario grado de exigencia de responsabilidad jurídica y política ante la crisis; de otra, la corresponsabilidad y progresividad de la presión fiscal no se ve que sea efectivamente corregida (al contrario, se incide en la imposición al consumo); y además, se producen recortes sociales, a la par que, en algunos Estados (como en España), aumenta críticamente el desempleo. En este sentido, de particular interés resulta el manifiesto ;Indignaos!, de Hessel, S. (y publicado en España en Destino, Barcelona, 2011, con trad. de Moreno LanasPa, T. y prólogo de SAMPEDRO, J. L.), en torno al cual, precisamente, se articularon buena parte de las movilizaciones sociales de 2011 en Europa. Otra cosa es, al tiempo, que el desapego social quepa llegar a crispación y conflicto social, ante la violencia que para los ciudadanos suponen unas medidas, fundamentalmente orientadas a la reducción de garantías sociales, que los dejan desamparados ante la crisis.

${ }^{42}$ Ante el nuevo aforisma de que «hemos vivido por encima de nuestras posibilidades», y de que «las generaciones futuras tendrán que asumir que vivirán en unas condiciones sociales y económicas inferiores a las presentes». De sumo interés, GRANELL TRIAS, F. «Las medidas contra la crisis, sus problemas y su impacto intergeneracional», Información Comercial Española, ICE: Revista de economía, núm. 850, 2009, Ejemplar dedicado a La primera crisis global: procesos, consecuencias, medidas, pp. 57 y ss. 
sonas; unos servicios que, junto a la protección laboral, han cualificado las condiciones de vida y de participación de los europeos, frente al resto de buena parte de la población mundial ${ }^{43}$.

Con esto, a su vez, nos situamos ante otra trama de políticas que (si bien a nivel estatal e interno, pero bajo cierta connivencia de la Unión), entiendo, repercuten también muy negativamente en relación a la identidad, como a la propia integración europea. Me refiero a la propagación de políticas populistas que inciden en el pluralismo, en general, y en las minorías, en particular, difícultando la integración multicultural de los individuos. Y es que, más allá de ciertas políticas en diversos Estados en relación a ciertas minorías ${ }^{44}$, está el avance democrático de partidos xenófobos y racistas en no pocos Estados europeos (Dinamarca, Holanda, Francia, Finlandia, Italia, Eslovaquia, Hungría y Grecia especialmente). Cuando la «inclusión del otro», en el ideario de HABERMAS ${ }^{45}$, se consideraba, por tiempo, no sólo como una de las respuestas necesarias para una globalización de valores, sino como uno de los contenidos del constitucionalismo más contemporáneo, parecería ahora desvanecerse en una fiebre populista a la sombra de la crisis económica, que se evidencia así, además de política, como cultural y de valores ${ }^{46}$; y más, cuando tal principio resulta consustancial con una integración de pueblos diversos en la Unión Europea $^{47}$. Difícilmente cabe profundizar en la integración europea cuando los diversos pueblos de Europa no son capaces de asumir las diferencias de los

${ }^{43}$ De «brasilización» de Europa (incluida Alemania), nos habla BECK, U. en «La política económica de la inseguridad», CuÉllar Menezo, J. (trad.), El País, 27 de mayo de 2012, http://elpais.com/elpais/2012/04/27/opinion/1335552968_819732.html (27/5/2012).

${ }^{44}$ Como el caso de Italia y Francia, en relación a los miembros de la etnia gitana (2010). O la crisis abierta entre ambos países con ocasión de la arribada masiva de refugiados egipcios, libios y tunecinos a Lampedusa y el ulterior cierre francés de fronteras (abril, 2011), y que concluyó con una declaración conjunta de Francia e Italia a favor de una reforma del Tratado Schengen a fin de introducir nuevos supuestos de restablecimiento de control fronterizo, en vez de haberse reforzado la solidaridad entre Estados con ocasión de emergencias humanitarias que tengan origen en la llegada ingente de inmigrantes; y ello, además, con el apoyo de Alemania y la propia Comisión. Al tiempo, la propuesta Danesa de restablecimiento de control de fronteras (mayo, 2011), bajo el pretexto de un mayor control de la criminalidad internacional, o las reformas constitucionales llevadas a cabo por Hungría (finales de 2011, y comienzos del 2012), limitando el pluralismo político (si bien, en esta ocasión, bajo el reparo y la vigilancia de la Unión Europea). Y más recientemente, el anuncio por miembros del gobierno de Cameron de posibles restricciones de flujos migratorios procedentes de Estados miembros de la Unión en crisis (julio, 2012).

${ }^{45}$ Habermas, L., La inclusión del otro. Estudios de teoría política, Vilar, G. y VeLASCo Arroyo, J. C. (trad.), Paidós Ibérica, Barcelona, 1999.

${ }^{46}$ Sobre el auge del populismo en la Democracia constitucional (y en particular para el caso italiano), vid. Ferrajoli, L., Poderes Salvajes. La crisis de la democracia constitucional, ANDRÉs IBÁÑEZ, P. (trad.), Trotta, Madrid, 2011.

${ }^{47}$ Von Bogdandy, A., «The European Union as Situation, Executive, and Promoter of the International Law of Cultural Diversity-Elements of a Beautiful Friendship», European Journal of International Law, núm. 19/2, 2008, pp. 241 y ss. 
otros, bajo un proyecto común de convivencia y gobierno jurídico, político, económico, social y cultural ${ }^{48}$.

\section{EL PROCESO DE CONSTITUCIONALIZACIÓN DE LA UNIÓN EU- ROPEA}

\subsection{Preliminares y orígenes; consolidación y crisis}

En un primer estadio de la integración regional europea al hilo de las originarias Comunidades Europeas (la Comunidad Europea del Carbón y del Acero, 1951, la Comunidad Económica Europea, 1957, y la Comunidad Europea de la Energía Atómica, 1957), con el Sputnik girando en torno a la Tierra (también, 1957), y en el marco de los antecedentes que la «aldea global» de McLUHAN (1962) suponía ya de un mundo cada vez más interconectado $^{49}$, recuérdese como tal integración (de unos pocos Estados, y en alto grado de homogeneidad económica, jurídica y política) se expresaba inicialmente como fundamentalmente económica y al margen del Derecho constitucional, dado que éste, por su parte, se entendía referido exclusivamente al Derecho de los Estados miembros en tal momento; lo que se postulaba, en cambio, era una integración y un Derecho comunitario al servicio de un mercado único y en busca de una identidad propia, mediante su autoafirmación ante los Estados y los Derechos estatales, como del Derecho internacional y de las organizaciones nacidas a su amparo. En tal sentido, precisamente, vendría a expresarlo el Tribunal de Justicia en dos históricas Sentencias: la Van Gend en Loos, de 5 de febrero de 1963 (Asunto 26/62), de acuerdo a la cual «la Comunidad constituye un nuevo orden jurídico de Derecho internacional, en beneficio del cual los Estados han limitado sus derechos soberanos»; y la Costa/ENEL, de 15 de julio de 1964 (Asunto 6/64), conforme a la cual, ahora, se habría "creado así un corpus normativo aplicable a sus nacionales y a sí mismos» al instituirse «un orden jurídico propio, integrado en el sistema jurídico de los Estados miembros [...] que se impone a sus respectivas jurisdicciones» ${ }^{50}$. De meras «asociaciones funcionales» vendría a hablar, al tiempo, IPSEN $(1972)^{51}$.

${ }^{48}$ Volviendo a las PIIGS, pero ahora con la contradicción entre una Europa católica y otra protestante, vid. BEDOYA, J. G., “"Cerditos” en la UE: ¿Son los países católicos manirrotos?», El País, 8 de enero de 2012 (en http://sociedad.elpais.com/sociedad/2012/01/07/ actualidad/1325970360_782608.html -5/6/2012-).

${ }^{49}$ Mcluhan, M., La galaxia Gutenberg: génesis del homo typographicus, Novella J. (trad.), Círculo de Lectores, Barcelona, 1998.

${ }^{50}$ Por ejemplo, en tal momento, ZweIGert, K., «Influencia del Derecho comunitario europeo en los órdenes jurídicos de los Estados que integran la Comunidad Europea», Boletín Mexicano de Derecho Comparado, núm. 6, 1969, pp. 623 y ss.

${ }^{51}$ Hipsen, H. P., «La posición jurídica de las Comunidades», Elías Méndez, C., StanLey K. y Arias PÉrez, R. (trad.), Revista de Derecho Constitucional Europeo, núm. 14, 2010, pp. 461 y ss. 
Por otra parte, y paralelamente, el desarrollo de la edad de los derechos, tras la segunda guerra mundial ${ }^{52}$, había tomado forma en la Europa occidental no sólo a nivel nacional (mediante la declaración y garantía jurídico-normativa de los derechos fundamentales en las respectivas Constituciones estatales que se vienen a aprobar) ${ }^{53}$, sino también a nivel regional con ocasión del Consejo de Europa (1949) y el Convenio Europeo para la Protección de los Derechos Humanos y de las Libertades Fundamentales $(1950)^{54}$, viniéndose a establecer, de este modo, un instrumento internacional en Europa de reconocimiento y promoción de derechos y libertades de las personas frente a los Estados partes: y ello, especialmente, mediante la institucionalización de una garantía política y jurisdiccional de los derechos ante la Comisión europea y el Tribunal Europeo de los Derechos del Hombre, respectivamente; y al tiempo, con la extensión y proyección (influencia) de la jurisprudencia de dicho Tribunal en tal labor de garantía de los derechos a otras manifestaciones jurisdiccionales existentes en Europa (según se viene a mostrar seguidamente) $)^{55}$.

Es en este contexto europeo declarativo y garantizador de derechos que, ante el reconocimiento del poder político y jurídico que las Comunidades Europeas estaban progresivamente acumulando (frente a los propios Estados que originariamente las conformaban), comenzara a plantearse la necesidad de la limitación jurídica de tal poder comunitario como garantía de los derechos y las libertades de los ciudadanos de los Estados miembros ${ }^{56}$. No es de extrañar,

\footnotetext{
${ }^{52}$ Por todos, BobBio, N. L'età dei diritti, Einaudi, Torino, 1992.

${ }^{53}$ Así, por ejemplo: FiORAVANTI, M., Los derechos fundamentales (Apuntes de historia de las

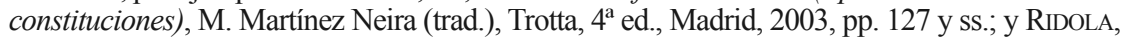
P., Diritti fondamentali (Un'introduzione), G. Giappichelli Editore, Torino, 2006, pp. 93 y ss.

${ }^{54} \mathrm{De}$ ahí que, a la hora de hablar de la constitucionalización regional europea debamos también especificar a qué Europa nos referimos, por cuanto que cabe plantear dicha constitucionalización en relación a diversos espacios europeos; así, sobre un «Derecho europeo en sentido amplio», en tanto que conformado por el Derecho de la Unión Europea y el referido Convenio Europeo de Derechos Humanos, cfr. HÄBERLE, P., «El Estado constitucional europeo», Balaguer CAllejón, F. (trad.), Revista de Derecho Constitucional Europeo, núm. 11, 2009, p. 426.

${ }^{55} \mathrm{Al}$ respecto, por ejemplo, SÁrz Arnaiz, A., «El convenio de Roma, el Tribunal Europeo de Derechos Humanos y la cultura común de los derechos fundamentales en Europa», en AAVV Estudios sobre la Constitución Española: homenaje al profesor Jordi Solé Tura (II), CARRILlo, M. (coord.), Cortes Generales/Centro de Estudios Políticos y Constitucionales/Universitat de Barcelona/Ajuntament de Mollet del Vallès, Madrid, 2008, pp. 2039 y ss.; o Stone SweEt, A., «A cosmopolitan legal order: Constitutional pluralism and rights adjudication in Europe», Global Constitutionalism, núm. 1, 2012, pp. 53 y ss.

${ }^{56}$ Mas sin una declaración de derechos a nivel comunitario, en este momento (a salvo, claro está, de las llamadas libertades comunitarias); y ello, por tanto, en contradicción con el constitucionalismo normativo asentado en buena parte de los Estados miembros de las Comunidades Europeas, sin perjuicio de la posibilidad de una garantía de derechos y libertades en cuanto que efectivamente garantizada mediante una adecuada organización política y jurídica del poder (sobre tal potencialidad, vid. SARTORI, G., Ingeniería constitucional comparada, Reyes Mazzoni, R. -trad.-, Fondo de Cultura Económica, México, 1994, pp. 211 y ss.).
} 
por tanto, que el propio Tribunal de Justicia viniera finalmente en sus Sentencias Stauder, de 12 de noviembre de 1969 (Asunto 29/69), Internationale Handelsgesellschaft, de 17 de diciembre de 1970 (Asunto 11/70), y Nold, de 14 de mayo de 1974 (Asunto 4/73), a afirmar (si bien con el propósito, tal vez, de mantener su monopolio sobre el juicio de validez del Derecho comunitario) la integración ya de los derechos fundamentales como principios generales del Derecho comunitario, de manera que éste se sujetara a ellos a partir de «las tradiciones constitucionales comunes de los Estados miembros», de acuerdo al referido Convenio Europeo de Derechos Humanos y las Constituciones de los Estados miembros; y con esto, si bien de manera pretoriana, la constatación, definitivamente, del reconocimiento de la limitación jurídica del poder de las Comunidades en garantía de los derechos y las libertades de los ciudadanos, en obvia correspondencia al Derecho constitucional de los Estados miembros ${ }^{57}$ en cuanto que «Derecho constitucional común europeo», según las tesis de HäBERLE (1991) ${ }^{58}$. De ahí que, al menos, podamos hablar ya en este momento de un pre-estadio constitucional a nivel europeo, sin perjuicio de las reticencias de ciertos Tribunales Constitucionales que, aun aceptando la primacía del Derecho comunitario frente a los Derechos nacionales, se postulaban como guardianes últimos de los derechos fundamentales garantizados en sus respectivas Constituciones ante aquél (por todas, la Sentencia Solange I, de 29 de mayo de 1974, del Tribunal Constitucional Federal alemán, y de manera más matizada, la Solange II, de 22 de octubre de 1986) $)^{59}$, y sin que las Comunidades hubieran ratificado el referido Convenio Europeo de Derechos Humanos ${ }^{60}$. Mas con ello, al tiempo, desarrollándose una consideración comunicativa del Derecho europeo y de los Derechos constitucionales estatales, a partir del protagonismo dialéctico que se da entre el Tribunal de Justicia y los Tribunales Constitucionales nacionales, llegando a nuestros

${ }^{57}$ Por ejemplo, vid. CÁmara Villar, G., «Los derechos fundamentales en el proceso histórico de construcción de la Unión Europea y su valor en el Tratado Constitucional», Revista de Derecho Constitucional Europeo, núm. 4, 2005, pp. 9 y ss.

${ }^{58}$ HÄBerle, P., «Derecho Constitucional Común Europeo», Mikunda Franco, E. (trad.), Revista de Estudios Políticos, núm. 79, 1993, pp. 7 y ss. Y con ello, entroncando con el desarrollo histórico de un Derecho común en Europa, si bien ahora más allá del Derecho privado; al respecto, de interés, Grossi, P., L'Europa del diritto, Editori Laterza, Roma-Bari, 2007, y StolleIs, M., La Historia del Derecho como obra de arte, GutiérREZ GutíERrez, I. (trad.), Comares, Granada, 2009.

${ }^{59}$ En general, sobre tal articulación de los derechos fundamentales en las jurisprudencias comunitaria y constitucional de los Estados miembros en tal periodo, vid., entre otros, Alonso García, R., Derecho comunitario (Sistema constitucional y administrativo de la Comunidad Europea), Centro de Estudios Ramón Areces, Madrid, 1994, Cap. VIII.

${ }^{60}$ Con las consiguientes limitaciones que ello supone en relación a la consideración de los derechos fundamentales en tanto que principios del Derecho comunitario, según viene a señalar DíEz-PICAZo, L. M., en «La relación entre la Unión Europea y el Convenio Europeo de Derechos Humanos», Teoría y Realidad Constitucional, núm. 15, 2004, pp. 159 y ss. 
días ${ }^{61}$, y al que habría que sumarse también su interacción con el Tribunal Europeo de Derechos humanos ${ }^{62}$; una interacción, sin duda, fundamental para comprender el desarrollo de la ulterior constitucionalización europea (de la que seguidamente se viene a tratar). Con todo, en este período comenzaría a hablarse ya de los Tratados constitutivos de las Comunidades a modo de Constitución, en tanto que articulación normativa básica y superior de la ordenación política de éstas en tal momento ${ }^{63}$; sin embargo, no nos resulta adecuado dicha consideración, por cuanto que la concepción dominante de Constitución en Europa en tal momento, y más allá de su clásica referencia al Estado, responde a una serie de postulados sustantivos y formales que quedan aún lejos de las Comunidades (y de los Tratados constitutivos) en dicho período.

Como segundo momento evolutivo está, a finales ya del Siglo pasado tras la caída del muro de Berlín (1989), y con BECK y GIDDENS (1998 y 1999, respectivamente), el reconocimiento de una nueva concepción del mundo caracterizada por su mayor complejidad y contradicción, el desarrollo tecnológico y del riesgo, y la difuminación de las fronteras y la soberanía de los Estados en relación, especialmente, al mercado y la economía (conforme se ha adelantado $)^{64}$; un mundo en el que la regionalización económica emprendida en Europa se postulaba entonces como un referente en Derecho comparado, y a la luz de lo cual se procedería a su profundización política a fin de permitirle progresar en el nuevo contexto global enunciado (sin perjuicio de

${ }^{61}$ De interés, Poiares Maduro, M. «Las formas del poder constitucional de la Unión Europea», De Elera, A. (trad.), Revista de Estudios Políticos, núm. 119, 2003, pp. 11 y ss.

${ }^{62}$ Desde esta perspectiva, cfr. Rodríguez Iglesias G. C. y A. Valle Gálvez, A., «El Derecho comunitario y las relaciones entre el Tribunal de Justicia de las Comunidades Europeas, el Tribunal Europeo de Derechos Humanos y los Tribunales Constitucionales nacionales», Revista de Derecho Comunitario Europeo, núm. 2, 1997, pp. 239 y ss. Asimismo de interés, pero desde la perspectiva de los Tribunales constitucionales (y en particular, del español), Guillén LóPEz, E., «The impact of the European Convention of Human Rights and the Charter of Fundamental rights of the European Union on Spanish constitutional law: Make a virtue of necessity», en AAVV Human rights protection in the European legal order: The interaction between the European and the national courts, POPELIER, P., VAn de Heyning, C. y Van Nuffel, P. (ed.), Intersentia, Cambridge-Antwerp-Portland, 2011, pp. 309 y ss.

${ }_{63}$ Por ejemplo, Sánchez Rodríguez, L. I., «Los Tratados constitutivos y el derecho derivado», en AAVV Tratado de Derecho Comunitario Europeo (Estudio sistemático desde el Derecho español) (I), GARCÍA DE EnTERría, E.; GonzÁlez CAMPOS, J. D. y MuÑOZ MACHADO, S. (dir.), Civitas, Madrid, 1986, pp. 316 y ss. Y al tiempo, desde tal perspectiva, equiparando la actuación del Tribunal de Justicia con una jurisdicción constitucional, vid. nuevamente, Rodríguez Iglesias, G. C. pero ahora con BAQuero, J., «Funciones constitucionales del Tribunal de Justicia de las Comunidades Europeas», Fundamentos: Cuadernos monográficos de teoría del estado, derecho público e historia constitucional, núm. 4, 2006, pp. 291 y ss.

${ }^{64}$ Respectivamente (y otra vez), BECK, U., ¿Qué es la globalización?...cit., y GIDDENS, A., Un mundo desbocado... cit. 
considerar, no obstante, a la propia Europa como actor y promotor de la misma globalización $)^{65}$. A tal perspectiva responde, precisamente, la irrupción del debate constitucional para Europa tanto a nivel institucional (con los Proyectos del Parlamento Europeo Spinelli, de 1984, y Herman, de 1994) ${ }^{66}$, como académico (por ejemplo, GrimM y HABERMAS) ${ }^{67}$, para finalmente limitarse a la evolución de las Comunidades europeas en Unión Europea, a partir del Tratado de Maastricht (1992), ulteriormente perfeccionado con el de Ámsterdam (1997), y la disposición de una moneda única, el euro, si bien reducida a una parte de la Unión y sin una consecuente unidad financiera a su servicio. Sin embargo, dicha profundización política y jurídica, tanto frente a los Estados como respecto a los propios ciudadanos, vendría también acompañada de una institucionalización en los referidos Tratados de diversos contenidos propiamente constitucionales con los que compensar ante éstos el aumento político y jurídico de la integración europea, conteniéndolo. Nos referimos así a la previsión de un mayor peso del Parlamento Europeo en la toma de decisiones de la Unión, junto con el fomento del principio democrático en Europa especialmente a partir de la institucionalización de una ciudadanía europea; además, el reconocimiento en los Tratados del principio de subsidiariedad (con la previsión, también, de la intervención de los Parlamentos nacionales en las tomas de decisiones a nivel europeo) y un mayor detalle en el alcance de las competencias/políticas de la Unión; la positivización del referido Derecho constitucional común europeo, en tanto que «tradiciones constitucionales comunes a los Estados miembros» en materia de derechos fundamentales y conforme al Convenio Europea para la Protección de los Derechos Humanos ${ }^{68}$; y la extensión, en mayor o menor grado, de la acción europea en materias como inmigración o justicia, de indudable calado constitucional ${ }^{69}$.

Pero con ello (el nuevo poder que asume la Unión Europea, con la correlativa pérdida que esto supone para los Estados miembros, junto con la re-

${ }^{65}$ En tal sentido, cfr. MeUnIER, S. y JACOBY, W., «Europe and Globalization», en AAVV Research Agendas in European Union Studies: Stalking the Elephant, EgAN, M.; NugENT, N. y PAterson, W. E. (edit.), Palgrave MacMillan, Houndmills, 2010, pp. 354 y ss.

${ }^{66} \mathrm{Al}$ respecto de éstos, vid. GARCÍA DE ENTERRÍA, E., «El proyecto de Constitución europea», Revista Española de Derecho Constitucional, núm. 45, 1995, pp. 9 y ss.; y MANGAS MARTín, A., «Reflexiones sobre el Proyecto de Constitución europea ante la perspectiva de la reforma de 1996», asimismo Revista Española de Derecho Constitucional, núm. 45, 1995 , pp. 135 y ss.

${ }^{67}$ Respectivamente, Grimm, D., «Una costituzione per l'Europa?», Fiore, F. (trad.), y Habermas, J., «Una costituzione per l'Europa? Osservazioni su Dieter Grimm», CePPA, L. (trad.), ambos en AAVV Il futuro dellacostituzione... cit., pp. 339 y ss., y 369 y ss.

${ }^{68}$ Sobre los derechos fundamentales en Europa como factor de constitucionalización de la misma, vid. Pizzorusso, A. Il patrimonio costituzionale europeo, Il Mulino, Bologna, 2002.

${ }^{69}$ AA.VV. El Tratado de Amsterdam, Oreja Aguirre, M. (dir.), Fonseca Morillo, F. (coord.), McGraw Hill, Madrid, 1998. 
ferida institucionalización de contenidos constitucionales en los Tratados), dando lugar a una nueva concepción compartida del Derecho constitucional, de nuevo según las tesis de HäBERLE; es decir, cómo en Europa el Derecho constitucional, de un lado, deja progresivamente de identificarse con los Estados, al extenderse al Derecho europeo, a la par que, de otro, el marco constitucional que finalmente ordena y limita el ejercicio del poder y determina el estatus de los ciudadanos europeos ya no se encuentra exclusivamente en los Derechos nacionales, al resultar compartido con el Derecho europeo y el Convenio Europeo de Derechos Humanos ${ }^{70}$. Y al hilo de esto, el desarrollo de nuevas perspectivas del Derecho constitucional, en tanto que europeo ahora, y en el doble sentido de alcanzar tanto el Derecho de la Unión Europea, como el de los Estados miembros. Son así, por ejemplo, las tesis de PERnICE en torno a la idea del multilevel constitutionalism (1999) ${ }^{71}$; las de BALAGUER CALLEJÓN, acerca de la «fragmentación del poder constituyente» $(2002)^{72}$; o las de CRUZ Villalón, sobre un hipotético «bloque europeo de la constitucionalidad» $(2002)^{73}$. Pero también, la consideración incluso de la integración europea desde el federalismo, con VON BOGDANDY ${ }^{74}$, para llegar a afirmar la Unión Europea como un «orden federal» construido desde los Estados (en tanto que abiertos y/o cooperativos), a la que dotan de legitimidad (según WAHL, ahora $)^{75}$.

${ }^{70}$ HÄBERLE, P. por ejemplo «Europa como comunidad constitucional en desarrollo», Balaguer Callejón, F. (trad.), Revista de Derecho Constitucional Europeo, núm. 1, 2004, pp. 12 y ss.

${ }^{71}$ PERNICE I.: «Multilevel constitutionalism and the Treaty of Amsterdam: European constitution-making revisited», Common Market Law Review, núm. 36, 1999, pp. 703 y ss.; y, ulteriormente, «Multilevel Constitutionalism in the European Union «, European Law Review, núm. 5, 2002, pp. 511 y ss.

${ }^{72}$ BALAguer CALlejón, F. «El status constitucional de la reforma y la fragmentación del poder constituyente», en AAVV La Democracia constitucional. Estudios en homenaje al Profesor Francisco Rubio Llorente (I), ARAgón Reyes, M.; JimÉnEz CAMPo, J. y SoloZÁBAL EchaVARría, J. J. (presentación), Congreso de los Diputados/Tribunal Constitucional/Universidad Complutense de Madrid/Fundación Ortega y Gasset/Centro de Estudios Políticos y Constitucionales, Madrid, 2002, pp. 99 y ss. Asimismo, en esta línea, MuÑoz Machado, S. Constitución, Iustel, Madrid, 2004, pp. 322 y ss.

${ }^{73}$ Cruz Villalón, P., La Constitución inédita: estudios ante la constitucionalización de Europa, Trotta, Madrid, 2004. Y en la órbita de tal concepción, también, Bustos GisBERT, R. La Constitución red: un estudio sobre la supraestatalidad y Constitución, Instituto Vasco de Administración Pública, Bilbao, 2005, en especial pp. 177 y ss.

${ }^{74}$ Dado que garante de un orden colectivo, a la par integración política sobre un territorio y una ciudadanía; Von BogDANDY, A., «The European Union as a Supranational Federation: A conceptual attempt in the light of the Amsterdam Treaty», Columbia Journal of European Law, núm. 6/1, 2000, pp. 27 y ss.

${ }^{75}$ WAHL, R., «¿Cabe explicar la Unión Europea mediante conceptos fundamentales de Teoría del Estado?», Teoría y Realidad Constitucional, núm. 18, 2006, en especial pp. 117 y ss. 
Sin embargo, una cosa era enunciar, prever y advertir cambios, y otra los cambios mismos que se desarrollan aceleradamente desde comienzos del Siglo XXI, y que encontrarían plasmación: de un lado, y dramáticamente, en los atentados del 11.S de 2001 (y más tarde, ya en Europa, el 11 de marzo de 2004 en Madrid, y el 7 de julio de 2005 en Londres), constatando el alcance de una nueva sociedad del riesgo global; de otro, la aparición de nuevas economías emergentes (fundamentalmente, las BRIC), amenazando el dominio económico norteamericano y europeo; más adelante, la todavía vigente crisis económica del 2007; y recientemente, la revolución ciudadana a través de las redes sociales como expresión de nuevas formas de conciencia y participación política (primavera de 2011) ${ }^{76}$.

Sin duda, y a la sombra de los cambios que venían ya advirtiéndose a finales del Siglo pasado, la Unión Europea decidió progresar una vez más, cuantitativa y cualitativamente, en su integración política y jurídica a fin de atender a los nuevos retos que venía suponiendo la globalización (terrorismo, medio ambiente, tecnología e inmigración), programando su extensión a nuevos espacios geográficos (hasta llegar a los 27 Estados miembros actuales -28 con Croacia, para el 2013-, y aumentando así el conflicto propio de un mayor pluralismo en su seno) y materiales (afectando, por tanto, a cuestiones todavía más sensibles para el núcleo constitucional de los respectivos Estados miembros) $)^{77}$. Pero con ello, confrontándose nuevamente con la necesidad/conve-

${ }^{76} \mathrm{Al}$ respecto de esto último, vid. Presno Linera, M. A., «El 15M y la democracia real», El cronista del Estado Social y Democrático de Derecho, núm. 25, 2012, pp. 38 y ss.; también de interés, GuILlÉn LóPEZ, E., «El 15-M desde la óptica del socialismo democrático», asimismo en El cronista del Estado Social y Democrático de Derecho, pero ahora núm. 29, 2012, pp. 80 y ss.

${ }^{77}$ El proceso de integración europea, en sus inicios y en relación al mercado, ciertamente supuso una primera respuesta eficiente a una incipiente globalización, sin perjuicio de poder considerar, paralelamente, tal proceso de integración como motor mismo (o al menos catalizador) de aquélla (no se olvide cómo las Comunidades Europeas nacieron en torno al mercado, lo que ha dejado, a la postre, un poso economicista; cfr. Maestro Buelga, G., «Estado de mercado y Constitución económica: algunas reflexiones sobre la crisis constitucional europea», Revista de Derecho Constitucional Europeo, núm. 8, 2007, pp. 43 y ss.). Y es que mediante dicha integración europea unos pocos Estados, y en alto grado de homogeneidad económica, jurídica y política (inicialmente), consiguieron formar una masa crítica geográfica, demográfica, económica, política y jurídica suficiente como para competir con otros Estados (fundamentalmente, Estados Unidos, la URSS y Japón) y contrarrestar la acción de gigantescas corporaciones privadas que actuaban en el mercado internacional. Sin embargo, tras la caída del bloque soviético y conforme en el mercado global han aparecido nuevos Estados económicamente emergentes (los BRIC), a la par que dichas corporaciones han evolucionado en el ecosistema global, junto con el protagonismo alcanzado por los fenómenos anteriormente anotados (tecnología, terrorismo, clima e inmigración), se ha hecho necesario una ampliación tanto geográfica como sustantiva de la integración en Europa, según se advierte en atención a la progresiva reforma de los Tratados originarios llevada a cabo desde la década de los noventa del siglo pasado, hasta la actualidad. Al respecto 
niencia de profundizar en la constitucionalización de la Unión Europea ${ }^{78}$, para finalmente advertir, no obstante, su ulterior fracaso con ocasión de: la solemne proclamación de la Carta de los Derechos Fundamentales de la Unión Europea, mas sin entrar inicialmente en vigor (Consejo de Niza, 2000); el malogrado Tratado por el que se establece una Constitución Europea, a pesar de sus deficiencias constitucionales (2004); y el reticente y limitado Tratado de Lisboa $(2007)^{79}$.

Al respecto de este último, y en cuanto que marco vigente del Derecho originario europeo (TUE, TFUE y CDFUE), hemos de señalar dos cuestiones. La primera es la contradicción que supone la huida en el mismo de todo elemento expresamente constitucional, como se planteaba en el anterior y malogrado Tratado constitucional, para luego finalmente recoger no pocos aspectos de él, como son (entre otros): la profundización, nuevamente, del principio democrático, y ello tanto en relación al Parlamento Europeo, colocándose en un nivel más cercano al Consejo (pero todavía a su rebufo), como respecto a los parlamentos nacionales (e incluso regionales), dándoles mayor protagonismo (a través de la subsidiariedad); el reconocimiento jurídico y normativo, por fin, de la Carta de Derechos Fundamentales de la Unión Europea, y en la dicción del Tratado constitucional; una nueva y más definida sistematización de las fuentes del Derecho derivado europeo, aunque a medio camino entre las novedades que suponía el Tratado constitucional y el sistema preexistente;

de tal ampliación cuantitativa y cualitativa de la integración europea, su progresiva extensión a nuevos espacios, como su apertura a cuestiones más sensibles para el núcleo constitucional de los respectivos Estados miembros, no se ha producido sin embargo con la homogeneidad con la que inicialmente nació la integración europea, lo que, lógicamente, ha venido a aumentar el conflicto, dado el mayor pluralismo existente. A su vez determinados déficits de la integración europea, como el reconocimiento y garantía de los derechos fundamentales ante el emergente poder europeo, como sus carencias democráticas (que desde el inicio han venido siendo denunciados), si bien resultaban amortiguados por los sistemas constitucionales de los Estados miembros, resultan ahora potenciados dada la incidencia de la integración en aspectos más sensibles constitucionalmente, a la par que el Derecho constitucional de los Estados se muestra desdibujado por la acción del Derecho de la Unión Europea. Muestra de ello es, sin duda, la progresiva aparición al tiempo de conflictos constitucionales protagonizados por las jurisdicciones constitucionales nacionales ante el Derecho europeo (al respecto, por ejemplo, VeCCHIO, F. «Un nuevo capítulo en la "saga" del "Data retention": el Tribunal Constitucional de la República Checa declara la inconstitucionalidad de los actos de transposición de la Directiva 2006/24/CE», SÁnchez BARrilao, J. F. -trad.-, Revista de Derecho Constitucional Europeo, núm. 16, 2011, en http://www.ugr.es/ redce /REDCE16/articulos/12bisFVecchio.htm -11/6/2012-).

${ }^{78}$ Por todos, sobre la necesidad de una Constitución para Europa en aquel momento, HABERmas, J. en su clásico «Por qué Europa necesita una Constitución», New Left Review, núm. 11, 2001, pp. 5 y ss., en http://www.newleftreview.es/?lang=es\&issue=11 $(05 / 02 / 2012)$.

${ }^{79}$ Para una crónica de este período, vid. Mariscal, N., Más allá de Lisboa: Horizontes europeos, Tecnos, Madrid, 2010. 
y la plena comunitarización del espacio de libertad, justicia y seguridad. Y en tal marco, que quepa reafirmarse una constitucionalización, aun limitada, del Derecho europeo ${ }^{80}$.

La segunda cuestión que plantea el Tratado de Lisboa, no obstante ahora, es cómo los avances constitucionales y de mayor integración política que supone este Tratado (al margen, eso sí, de la rebaja de expectativas constitucionales que se venían planteando) parecen llegar tarde al entrar el Tratado de Lisboa en vigor ( 1 de diciembre de 2009) en un momento de crisis, no ya económica y global (la de 2007, todavía), sino financiera y específicamente europea (con el rescate de Grecia ya en mayo de 2010, y los de Irlanda, Portugal y España en noviembre de 2010, mayo de 2011 y julio de 2012, respectivamente), y que encuentra su origen, en gran medida, en la falta de integración financiera entorno al euro (según se ha adelantado) ${ }^{81}$ : crisis, finalmente, no sólo económica, sino política, social y de valores (también, según se ha adelantado $)^{82}$.

\subsection{Momento actual, urgencia y cuestiones abiertas}

Es de este modo que la apuesta de una mayor integración política, financiera y social en la zona euro tome de nuevo presencia, ante la referida situación de crisis en la que nos encontramos (nuevamente, jmás Europa!); y ello, y otra vez con HABERMAS, con el horizonte de una auténtica Constitución europea ${ }^{83}$.

Cualquiera que sea la salida final del túnel en el que se encuentra la Unión Europa, lo que parece claro es la extrema urgencia y necesidad de una respuesta que suponga mayor integración; y consiguientemente, la correspondencia de que tal aumento de integración venga acompañada de mayores dosis de Derecho constitucional en el seno de los Tratados constitutivos de la Unión, a fin de contrarrestar la pérdida de poder que dicha integración haya de suponer para los Estados miembros, a la par que garantizar un gobierno más plural, democrático y social. Si sobre lo primero no tenemos duda, en razón a la extrema gravedad de la situación, sobre lo segundo, en cambio, está por ver, dada la deriva tecnócrata y ultraliberal que últimamente parece recorrer Europa, la desavenencia que entre

${ }^{80}$ Balaguer Callejón, F., «La Constitución Europea tras el Consejo Europeo de Bruselas y el Tratado de Lisboa», Revista de Derecho Constitucional Europeo, núm. 8, 2007, pp. 11 y ss.

${ }^{81}$ Así lo destaca Tajadura TejadA, J. en su «Epílogo» a El futuro de Europa (Luces y sombras del Tratado de Lisboa), Comares, Granada, 2010, pp. 119 y ss.

${ }^{82}$ De interés, y desde la propia Unión Europea, el «Informe al Consejo Europeo del Grupo de Reflexión sobre el futuro de la UE en 2030», presentado ya en mayo de 2010, en http://www.consilium.europa.eu/uedocs/cmsUpload/Reflection_ES_web.pdf (4/3/2012).

${ }^{83}$ Habermas, J. «La crisis de la Unión Europea a la luz de una constitucionalización del Derecho internacional. Un ensayo sobre la Constitución de Europa», HeRnández I Dobon, F. J. y Herzog, B.(trad.), en La Constitución de Europa, Trotta, Madrid, 2012, pp. 39 y ss. 
los Estados miembros cabe apreciar, y las más que limitadas respuestas hasta ahora ofrecidas (en particular, en el Consejo Europeo de 8 y 9 de diciembre de 2011, y en los de 30 de enero y 1 de marzo de 2012 con el Tratado de Estabilidad, Coordinación y Gobernanza en la Unión Económica y Monetaria -suscrito por los vigentes Estados miembros de la Unión Europea, salvo la República Checa y el Reino Unido- $)^{84}$. Y al hilo de lo anterior, también, la necesidad de consecuentes reformas constitucionales a nivel interno, a fin de compensar su estadio constitucional propio con la hipotética profundización de la integración europea ${ }^{85}$, más allá, sin embargo, de las propuestas en torno a la constitucionalización de la conocida como «regla de oro» (al impulso de la reforma constitucional alemana de 200986, y el referido Consejo Europeo de 8 y 9 de diciembre de 2011) en relación a la limitación del gasto público (ya, el vigente art. $135 \mathrm{CE}$, a la vista de la reforma constitucional española de 27 de septiembre de 2011) ${ }^{87}$.

No obstante lo anterior, y al día de hoy, se mantienen las previsiones de recesión económica ${ }^{88}$, lo que va a poner en serias dificultades no sólo la materialización de los acuerdos más arriba referidos, sino la mera recuperación económica al tiempo, dada la más que limitada capacidad de reacción económica

${ }^{84}$ Un Tratado que, de un lado, tiene naturaleza de tratado intergubernamental, a fin de reforzar el pilar económico de la unión económica y monetaria, así como la coordinación de las políticas económicas de los Estados firmantes y la mejora de la gobernanza de la zona del euro (art. 1), y por tanto sin ser un Tratado modificativo del Derecho originario de la Unión; y de otro, refuerza la integración interestatal en relación a la disciplina presupuestaria, mas sin progresar en una auténtica y suficiente integración política, democrática y solidaria. Al respecto de dicho Tratado, vid. EmBID Irujo, A., La constitucionalización de la crisis económica, Iustel, Madrid, 2012, pp. 125 y ss.

${ }^{85}$ En tal sentido, por ejemplo, RuBIo LlORENTE, F., «La constitucionalización del proceso de integración de Europa», Revista de Occidente, núm. 284, 2005, pp. 5 y ss.

${ }^{86}$ Entre otros, vid.: ARROYO GIL, A., «La reforma constitucional de 2009 de las relaciones financieras entre la Federación y los Länder en la República Federal de Alemania», Revista d'Estudis Autonòmics i Federals, núm. 10, 2010, pp. 40 y ss.; y BIFUlCO, R., «Il pareggio di bilancio in Germania: una riforma costituzionale postnazionale?», Rivista della Associazione Italiana dei Costituzionalisti, núm. 3/2011, http://www.rivistaaic.it/articolorivista/il-pareggiodi-bilancio-germania-una-riforma-costituzionale-postnazionale (16/1/2012).

${ }^{87}$ Para una preliminar aproximación a dicha reforma, vid. la encuesta publicada en el núm. 93 de la Revista Española de Derecho Constitucional de 2011, que, bajo el título de «La reforma del artículo 135 CE» (pp. 159 y ss.), recoge comentarios (en uno y otro sentido) de Álvarez Conde, E.; Albertí Rovira, E.; Aragón Reyes, M.; Bastida FreiJedo, F. J.; CÁmara Villar, G.; De Carreras Serra, F.; CASCAJo Castro, J. L.; De Esteban, J. y Pérez Royo, J.; asimismo de interés, en dicho núm., RUBIo LLORENTE, F., «La reforma del artículo 135 de la Constitución» (pp. 204 y ss.). También, y en tono crítico, SÁnchez BARRILAO, J. F., «La crisis de la deuda soberana y la reforma del artículo 135 de la Constitución española» (en prensa).

${ }^{88}$ Comisión Europea, «Interim Forecast. February 2012», en http://ec.europa.eu/economy_finance/articles/eu_economic_situation/pdf/2012/2012-02-23-interimforecast_en.pdf (5/3/2012); o OCDE, «OECD Economic Outlook, May 2012», en http://www.keepeek.com/Digital-Asset-Management/oecd/economics/oecd-economic-outlook-volume-2012-issue-1_eco_outlook-v2012-1-en (22/5/2012). 
y social que aún se conserva (después de años de crisis) para hacer frente a dicha vuelta de tuerca; además, están las elecciones acaecidas en Grecia (mayo de 2012, y las ulteriores de 17 junio), y la todavía perspectiva abierta de una salida de ésta del euro (por cuanto que el referido pacto de gobierno en Grecia alivia ciertamente la situación, pero no la resuelve $)^{89}$; y por último, está la grave situación en la que se encuentra España, en especial con la crisis bancaria (con su rescate el 6 de junio de 2012 $)^{90}$, y el riesgo cierto de su extensión a otros Estados (y en particular a Italia), y el colapso del euro (con las consiguientes consecuencias a nivel mundial, como se debatiera ya en la reunión del G-20 en Los Cabos -México-, 18 y 19 de junio). De ahí, y en particular tras las elecciones presidenciales francesas de mayo de 2012 (y a instancia también de Estados Unidos, ante el riesgo de entrar en recesión, y el propio Fondo Monetario Internacional), la apertura, parece, de un debate en Europa en torno a efectivas políticas económicas tendentes al crecimiento, así como en relación a una mayor integración bancaria, fiscal y financiera; un debate propiciado no sólo desde algunos de los Estados (en especial, Francia), sino desde la propia Unión (la Comisión), además de otras potencias (así, el recién referido G-20, en sus conclusiones) ${ }^{91}$. Y un debate del que trae causa ya ciertos acuerdos adoptados recientemente, como es el Pacto para el Crecimiento y el Empleo (Consejo Europeo de 28 y 29 de junio de 2012), y el impulso de una mayor integración bancaria para la zona euro (Cumbre de la Zona del Euro, de 29 de junio de 2012) ${ }^{92}$.

Ante tal marco (con todo), es que nos sigamos preguntando cómo afrontar entonces la integración europea en relación a la globalización y la vigente crisis; sin embargo, y volviendo al pasado, no está de más plantearnos nuevamente qué ha sucedido, para finalmente poder progresar (aun con viejas respuestas).

\section{3. ¿QUÉ ES LO QUE HA PASADO PARA QUE LA CONSTITUCIONA- LIZACIÓN DE LA INTEGRACIÓN REGIONAL EUROPEA NO HAYA AVANZADO AL RITMO DE LA GLOBALIZACIÓN?}

Si la globalización viene de tiempo socavando la soberanía estatal y al propio Estado ${ }^{93}$, también la concepción de Constitución ha entrado en crisis, por

${ }^{89}$ No en vano, a finales de julio de 2012 se ha vuelto a poner en la palestra tal posibilidad, ante las reticencias del FMI de continuar con las ayudas a Grecia; cfr. http://economia.elpais.com/economia/2012/07/22/agencias/1342957591_506071.html (27/07/2012).

${ }^{90} \mathrm{Si}$ bien, finalmente, la petición se formalizaría a 25 de junio de 2012. Pero también, al poco tiempo, ante la necesidad de un nuevo rescate ante las dificultades de España para financiarse en los mercados secundarios a finales de julio de 2012.

${ }^{91} \mathrm{http} / / / \mathrm{g} 20 . \mathrm{org} / \mathrm{images} / \mathrm{stories} / \mathrm{docs} / \mathrm{g} 20 / \mathrm{conclu} / \mathrm{G} 20$ Leaders_Declaration_2012_1.pdf $(27 / 6 / 2012)$.

${ }_{92}$ Respectivamente, http://www.consilium.europa.eu/uedocs/cms_data/docs/pressdata/es/ec/131399.pdf; y http://www.consilium.europa.eu/uedocs/cms_data/docs/pressdata/es/ec/131362.pdf (27/07/2012).

${ }^{93}$ Por todos, CASSESE, S., La crisi dello Stato, Editori Laterza, Roma-Bari, 2001. 
cuanto que históricamente construida en torno a aquél ${ }^{94}$. Ante tal degradación del Estado y la Constitución se ha propuesto, entre otras respuestas, la constitucionalización de espacios superiores al Estado, como la mera extensión, de otro, de contenidos e instrumentos propiamente constitucionales a los mismos (desde

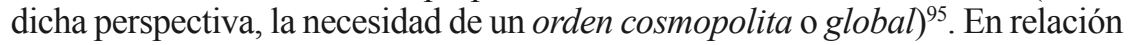

\footnotetext{
${ }^{94}$ Ya, Ferrajoli, L., La sovranità nel mondo moderno (Nascita e crisi dello Stato nazionale), Editori Laterza, Roma-Bari, 1997; y más recientemente, «La crisis de la democracia en la era de la globalización», Anales de la Cátedra Francisco Suárez, núm. 39, 2005, monográfico sobre Derecho y justicia en una sociedad global, pp. 37 y ss.

${ }^{95}$ Y ello no sólo profundizando en la eficiencia de los organismos internacionales ya existentes (reforzándolos al tiempo), sino en su diseño democrático con relación a los propios ciudadanos en la búsqueda de una mayor Democracia mundial. A estos efectos, se hace referencia a un nuevo concepto de ciudadanía capaz de compatibilizar la diversidad cultural y política, dependiendo del plano en que ésta se haga valer, como presupuesto, a su vez, de nuevas formas y niveles de gobierno y de una soberanía compartida en el marco de un constitucionalismo mundial. Entre otros, Held, D., La Democracia y el orden mundial (Del Estado moderno al gobierno cosmopolita), S. Mazzuca (trad.), Paidós, Barcelona, 1997 (y más recientemente, «Los principios del orden cosmopolita», Anales de la Cátedra Francisco Suárez, núm. 39, 2005, monográfico sobre Derecho y justicia en una sociedad global, pp. 133 y ss.); y JÁUREGUI, G., La Democracia Planetaria ... cit., passim. Por otra parte, y en relación a dicha extensión de contenidos e instrumentos propiamente constitucionales a nivel internacional (y regional), según se ha adelantado, ciertamente cabría hoy hablar de un Derecho constitucional común en tanto que generalización (en mayor o menor grado) de valores democráticos y humanos en normas internacionales (y regionales); y ello, en particular, a la vista de la experiencia europea, en torno, precisamente, al referido «Derecho constitucional común europeo». Se plantea así un marco de valores constitucionales más allá de cada una de las Constituciones escritas y de la soberanía estatal: un nuevo constitucionalismo sin fronteras (de pluralismo constitucionalizado nos habla ChITI, M. P. en Derecho administrativo europeo, ORTEGA, L. -trad.-, Civitas, Madrid, 2002, p. 46), que rompe con el clásico binomio Constitución-Estado, y nacido de la interpretación comparada de los textos constitucionales e instrumentos internacionales en garantía y protección de los derechos humanos, y de unas tradiciones jurídicas y políticas culturalmente compartidas de las que cabe extraer standars comunes (nuevamente HÄBERLE, P. pero ahora El Estado constitucional, FIX-FIERro, H. -trad.--, Universidad Nacional Autónoma de México, México, 2001, pp. 58 y ss., y 162 a 165). Sin embargo tal Derecho carece del sentido político constitutivo propio de las Constituciones normativas del siglo XX; no es que el Derecho constitucional común no posea cierto carácter político y democrático, sino que carece de la capacidad de ordenación, proyección y eficacia normativa que, aún con sus limitaciones, se sigue reconociendo todavía a la Constitución en la conformación política, jurídica y social de una comunidad. Así, acerca del déficit político de tal Derecho común, vid. FIORAVANTI, M. «Costituzione e política: bilancio di fine secolo», en AAVV La nuova età delle costituzioni (Da una concezione nazionale della democracia a una prospettiva europea e internazionale), ORNAGHI, L. (ed.), Il Mulino, Bologna, 2000, pp. 63 a 67; y sobre las «limitaciones del Derecho constitucional común europeo como instrumento de legitimidad», AZPITARTE SÁnCHEZ, M. «Del Derecho constitucional común europeo a la Constitución europea. ¿Cambio de paradigma en la legitimidad de la Unión?», Teoría y Realidad Constitucional, núm. 16, 2005, pp. 358 a 360 . Por último, de anarquía nos habla, al respecto de tal modelo, VeSPAZIANI, A. en «Il nomos dell'anarchia europea», en AAVV Poteri fluttuanti (Forme dell'anarchia contemporánea), Monceri, F. (ed.), Edizioni ETS, Pisa, 2011, pp. 151 y ss.
} 
a lo primero ${ }^{96}$, y junto a una hipotética constitucionalización de la comunidad internacional ${ }^{97}$, sí que se ha progresado a nivel de espacios regionales más limitados, a la par que más homogéneos constitucionalmente (sin perjuicio de la ulterior conexión de tales espacios con la comunidad internacional, como ya acontece, en cierto grado, en relación a los derechos humanos) ${ }^{98}$; y al hilo de ello, precisamente, la potenciación de la constitucionalización de la Unión Europea (conforme se ha apuntado en las anteriores páginas) ${ }^{99}$, aun reconociendo como ésta no ha avanzado al ritmo que ha mantenido la globalización en la última década, además de advertir, incluso, su estancamiento en los últimos tiempos (conforme venimos asimismo comentando).

La progresión constitucional que ha acompañado la integración europea, si bien ha conseguido compensar, aun parcialmente, el aumento de poder político y jurídico de la Unión en relación al principio democrático, como respecto a la garantía de los derechos de los ciudadanos, no ha alcanzado, sin embargo, a cubrir el total del traspaso del poder transferido a ésta por los Estados; y ello, en particular, a la hora de articular adecuadamente un gobierno efectivo y plural de Europa y de los Estados miembros, desde el Consejo, pues éstos han mantenido una privilegiada posición allí, además de en relación a los propios Tratados (los señores de los Tratados) ${ }^{100}$. Ahora bien, tal transferencia de poder de los Estados a la Unión ha debilitado finalmente la capacidad y el poder de aquéllos, como se está viendo en relación a la crisis de la deuda soberana de la zona euro; pero esto, sin que por otra parte haya dado lugar a suficiente poder en el seno de la Unión. Ciertamente puede afirmarse

${ }^{96}$ Entre otros, Teubner, G. «Societal Constitutionalism: Alternatives to State-centred Constitutional Theory», Storrs Lectures 2003/04, Yale Law School, en http://papers. ssrn.com/sol3/papers.cfm?abstract_id=876941 (05/02/2012).

${ }^{97}$ HABERMAS, J. especialmente: «¿Es posible una constitución política para la sociedad mundial pluralista?», Anales de la Cátedra Francisco Suárez, núm. 39, 2005, monográfico sobre Derecho y justicia en una sociedad global, pp. 107 y ss.; «¿Tiene todavía alguna posibilidad la constitucionalización del Derecho internacional?», en El Occidente escindido, LóPEZ De LizAGA, J. L. (trad.), Trotta, Madrid, 2006, pp. 113 y ss.; y «Constitucionalización del Derecho Internacional y problemas de legitimación de una sociedad mundial constitucionalizada», en ;Ay, Europa!, LóPez de Lizaga, J. L.; MAdrigal, P. y Gil Martín, F. J. (trad.), Trotta, Madrid, 2009, pp. 107 y ss. Pero dada la falta de presupuestos necesarios para ello (así, GIEGERICH, T. "The Is and the Ought of International Constitutionalism: How Far Have We Come on Habermas's Road to a «Well Considered Constitutionalization of International Law»?», German Law Journal, Vol. 10, núm. 1, 2009, pp. 31 y ss.

${ }^{98}$ Así, Gordillo PÉrez, L. I., Constitución y ordenamientos supranacionales, Centro de Estudios Políticos y Constitucionales, Madrid, 2012, en especial Parte IV (pp. 445 y ss.).

${ }^{99}$ Magníficamente descrita por GutiÉRrez GutiérREZ, I. en «De la Constitución del estado al Derecho constitucional para la Comunidad internacional», en AAVV La constitucionalización de la comunidad internacional, Peters, A.; AznAr Gómez, M. J y GutiÉRREZ GutiÉRrEZ, I. (coord.), Tirant lo Blanch, Valencia, 2010, pp. 15 y ss.

${ }^{100}$ Cfr. Balaguer Callejón, F., «Los tribunales constitucionales en el proceso de integración europea», Revista de Derecho Constitucional Europeo, núm. 7, 2007, pp. 327 y ss. 
así, y sin ningún género de duda, el progreso de la constitucionalización regional europea, mas con el precio de un debilitamiento de la normatividad de las Constituciones nacionales no compensado aún por una auténtica Constitución europea ${ }^{101}$.

Son tres, por tanto, las cuestiones que la anterior reflexión conlleva: la pérdida de poder público, tanto a nivel Europeo como estatal; el colapso de la gobernabilidad de la Unión Europea; y la pérdida de calidad normativa del Derecho constitucional y de la Constitución, asimismo a nivel europeo y estatal. Empezando por esta última cuestión, la tradicional flexibilidad del Derecho europeo, durante bastante tiempo, enarbolándose como eficiente respuesta ante la globalización, y viniendo, precisamente, si no a fomentar, sí que al menos a presuponer una mayor flexibilización del Derecho ${ }^{102}$; es por ello que resulte oportuno reflexionar al respecto.

En esta línea, entendemos, cabe advertir un doble grado de flexibilización formal del Derecho europeo. De una parte está su sistema de fuentes (hasta la reciente entrada en vigor, finalmente, del Tratado de Lisboa), en cuanto que falto de la sistematización propia de ordenamientos fundamentados en Constituciones normativas (como sucede en buena parte de sus Estados miembros), lo que le ha permitido una fluidez en el uso y en el ejercicio de sus categorías, y con ello un mayor grado de adaptación a las necesidades y coyunturas de cada momento ${ }^{103}$. De otro lado, y según lo

${ }^{101}$ De «desnormativización» nos hablaba ya BALAgUer CALLEJón, F. nuevamente, pero en «Fuentes del Derecho, espacios constitucionales y ordenamientos jurídicos», Revista Española de Derecho Constitucional, núm. 69, 2003, ejemplar dedicado a: XXV Aniversario de la Constitución (I), pp. 181 y ss.

${ }_{102}$ Sobre los cambios que la globalización supone en los paradigmas clásicos del Derecho, vid., por ejemplo, GARRIDO GÓMEZ, M. I., Las transformaciones del Derecho en la Sociedad Global, Aranzadi/Thomson Reuters, Pamplona, 2010.

${ }^{103}$ Ello ha sido obra, de una parte, de los propios órganos productores de normas en el marco comunitario, el Consejo y la Comisión, esencialmente, al flexibilizar los procesos normativos según venían determinados por el Derecho originario, y del propio Tribunal de Justicia, al tiempo, al admitir la legitimidad que de tal flexibilización aquéllos han hecho gala, en especial con ocasión de las directivas y la comitología (entre otros, Linde Paniagua, E. «El sistema de fuentes del Derecho de la Unión Europea», junto a Bacigalupo Saggese, M.; Fernández Rodríguez C. y Fuentetaja Pastor, J. A. en Principios de Derecho de la Unión Europea, 3. ${ }^{\mathrm{a}}$ ed., Colex, Madrid, 2006, pp. 405 y ss.). Pero además están los mismos Estados, en tanto que: integrantes de dichos órganos (en especial del Consejo); titulares del Derecho originario (en particular de los Tratados constitutivos y de las fuentes del Derecho previstas por éstos, por consiguiente), además de activos impulsores de acciones paralelas al Derecho de la Unión a fin de reforzar la cooperación entre los mismos en diversos espacios de la integración; y operadores coetáneos en la trasposición y aplicación del Derecho europeo a nivel interno. Otra cosa es, sin embargo, qué pueda pasar en el futuro a la luz del vigente sistema de fuentes del Derecho europeo diseñado en el Tratado de Lisboa, en el sentido de una mayor rigidez normativa en su realización de acuerdo a la acción de los actores más arriba referidos. 
apuntado, está la flexibilidad normativa del Derecho europeo, al no distinguirse expresamente entre normas y actos; la diferenciación, luego, entre normas enteramente jurídicas en todo su contenido y para todos sus destinatarios, como son las que tienen su origen en los reglamentos o en las decisiones (y en parte, en los propios Tratados), y otras únicamente en relación a los Estados y respecto a los fines de integración, como son las que se encuentran en las directivas (en principio) ${ }^{104}$; o la distinción entre normas en sentido estricto, y meros criterios normativos, dando lugar a un importante cuerpo de soft law de Derecho público a nivel europeo, e incluso otras meramente limitadas a prever, fomentando, la autorregulación y la normación técnica por los propios particulares ${ }^{105}$.

Ahora bien, el éxito de tal flexibilización sólo se entiende, frente a la facticidad de la globalización ${ }^{106}$, si junto al Derecho europeo se sitúan los Derechos de los Estados miembros y en particular sus Constituciones normativas, en un marco de cooperación ordinamental; y es que tanto el Derecho de la hoy Unión Europea, como los estatales, son Derechos parciales (según se ha adelantado), de manera que únicamente resultan completos en cuanto interactúan unos con otros. De este modo el Derecho Europeo, y con él su propia constitucionalización, es finalmente el resultado de ambos niveles ordinamentales, conformando, no obstante, una masa normativa de distintas intensidades: una más flexible, capaz de amortiguar, absorbiendo inicialmente, los empellones de la globalización; y otra de mayor dureza y rigidez (pero más frágil frente a un golpe directo de la globalización), capaz ahora de resistir tales envites una vez amortiguados por la primera. Así pues, entendemos, es la interacción de ambos Derechos, de diversa naturaleza y grado de flexibilidad y rigidez, lo que en verdad ha permitido, hasta no hace demasiado, resistir frente a la globalización; y consiguientemente, que el referido éxito del más maleable Derecho comunitario ante la globalización deba ser necesariamente compartido con los más compactos estatales ${ }^{107}$.

Pero tal flexibilización del Derecho europeo, en sentido estricto, ha terminado por afectar negativamente tanto al mismo Derecho europeo, como a los estatales. En cuanto a éstos últimos, dicha flexibilización ha venido progresivamente penetrando en las categorías propias de los sistemas de fuentes

${ }^{104}$ Por ejemplo, vid. Alguacil GonZÁlez-Aurioles, J., La directiva comunitaria desde la perspectiva constitucional, Centro de Estudios Políticos y Constitucionales, Madrid, 2004.

${ }^{105}$ En tal sentido, y con carácter general, vid. Alonso GARCÍA, R. Sistema jurídico de la Unión Europea, Thomson/Civitas, Pamplona, 2007, pp. 112 y ss., y 120 y ss.

${ }^{106}$ Facticidad, en su significación de realidad objetiva frente a normativismo; sobre tal oposición, vid. Habermas, J., Facticidad y validez (Sobre el Derecho y el Estado democrático de Derecho en términos de teoría del discurso), JiMÉnEz REDONDO, M. (trad.), 4. ${ }^{\text {a }}$ ed., Trotta, Madrid, 2005, en especial p. 68.

${ }^{107}$ En un sentido similar, vid. también LóPEZ PinA, A. y Gutiérrez GutiérREZ, I., Elementos de Derecho Público, Marcial Pons, Madrid-Barcelona, 2002, pp. 45 (in fine) y 46. 
de los Estados miembros ${ }^{108}$, devaluando, al tiempo, la normatividad de estos sistemas al amparo, en su mayoría, de Constituciones normativas (y sus respectivos sistemas de fuentes $)^{109}$, con lo que el grado de resistencia que los Derechos estatales venían otorgando al Derecho europeo, en sentido amplio, ha dejado de ser tal. Y respecto al Derecho europeo, estricto sensu, su propia flexibilización dio lugar a una complejidad tal de su sistema de fuentes que ha terminado por reducir su referida eficiencia ${ }^{110}$. Paralelamente, el propio Derecho europeo, como los estatales, se encuentra con la necesidad de arbitrar modos de producción del Derecho más expeditivos en su tramitación, a fin de procurar una más rápida adaptación normativa a unos tiempos cada vez más acelerados según marca la globalización ${ }^{111}$; y de ahí, a su vez, las dificultades que supone los procedimientos normativos europeos al requerir una multiplicidad de intervenciones institucionales, y por tanto requerir un tiempo del que no se dispone.

Además de lo anterior, la referida comunicación (diálogo) jurisdiccional que se plantea entre el Tribunal de Justicia y los Tribunales Constitucionales $^{112}$, aunque en plena consolidación ${ }^{113}$, encuentra paradójicamente cada vez

${ }^{108}$ Sobre tal flexibilización, cfr. SALVAdor Martínez, M., «Derecho constitucional comparado en el contexto de la integración supranacional y la globalización», Teoría y Realidad Constitucional, núm. 21, 2008, en especial pp. 394 y 395; asimismo, de interés, Romano, A., «El nivel constitucional y legal de las fuentes del derecho en los Estados de la Unión Europea», ARJona SÁnchez, M. (trad.), Revista de Derecho Constitucional Europeo, núm. 17, 2012, ab initio, en http://www.ugr.es/ redce/REDCE17/articulos/09_ROMANO.htm (27/07/2012).

${ }^{109}$ Sorrentino, F., Le fonti del diritto amministrativo (en Trattato di diritto amministrativo, G. Santaniello -dir.-, V. XXXV), CEDAM, 2004, Padova, pp. 5 y ss.

${ }^{110}$ Así, por ejemplo, Linde PaniaguA, E., «La simplificación normativa en la Constitución Europea», en AAVV La constitucionalización de Europa, CALONGE VELÁzQUEZ, A. (coord.), Comares, Granada, 2006, pp. 71 y ss. Otra cosa es, nuevamente, qué pueda suceder en relación al sistema de fuentes de Derecho derivado de la Unión al amparo del Tratado de Lisboa, sin perjuicio de reconocer los efectos adversos de la anterior situación de flexibilidad respecto a los sistema constitucionales internos.

${ }^{111}$ Y la tecnología; en tal sentido, ya, SÁnchez BARrilaO, J. F., «Tecnología, Democracia y fuentes del derecho», en AAVV Constitución y democracia: 25 años de Constitución democrática en España (I), García Herrera, M. A. (coord.), Centro de Estudios Políticos y Constitucionales, Madrid, 2005, pp. 467 y ss.

${ }^{112}$ Así, por ejemplo, AzPITARTE SÁnCHEZ, M., El Tribunal Constitucional ante el control del derecho comunitario derivado, Civitas, Madrid, 2002; o Alonso GARCÍA, R., Justicia constitucional y Unión Europea, Civitas-Aranzadi, Navarra, 2005.

${ }^{113}$ Desde tal perspectiva, cfr. ARROYO JIMÉNEZ, L., «Sobre la primera cuestión prejudicial planteada por el Tribunal Constitucional (Bases, contenido y consecuencias)», InDRET. Revista para el Análisis del Derecho, núm. 4, 2011, en http://www.indret.com/pdf/850_es.pdf (27/6/2012); también de interés, vid. AgUILAR CALAHORRO, A., «La primera cuestión prejudicial planteada por el Tribunal Constitucional al Tribunal de Justicia de la Unión Europea - Auto del Tribunal Constitucional 86/2011, de 9 de junio», Revista de Derecho Constitucional Europeo, núm. 16, 2011, en http://www.ugr.es/ redce/REDCE16/articulos/12AAguilar.htm (27/6/2012). 
más conflictos ante la comentada profundización de la integración europea en aspectos progresivamente más sensibles en relación a las Constituciones estatales, junto con la institucionalización de la garantía de las identidades constitucionales de los Estados miembros (art. 4.2 TUE) ${ }^{114}$. Y en tal sentido, la conveniencia de volver a plantearnos la necesidad de un instrumento normativo que resuelva finalmente las relaciones entre el ordenamiento estrictamente europeo y los nacionales ${ }^{115}$, y con ello resolver, a su vez, las relaciones entre el Tribunal de Justicia y los Tribunales Constitucionales; Tribunales, estos últimos, a su vez más plurales y diversos ante el ingreso últimamente de Estados en la Unión menos homogéneos que los concurrentes al inicio ${ }^{116}$.

Por otra parte, respecto al colapso del sistema de la gobernanza de la Unión Europea, la actual crisis europea, y de manera particular la que vive Grecia y España, ha puesto de manifiesto la incapacidad de la Unión para actuar como tal, ante el estupor, incluso, del resto del mundo. Así, y en relación a Grecia, recuérdese cómo la cumbre del G-20 celebrada en Cannes (Francia) los días 3 y 4 de noviembre de 2011 resultó eclipsada por el referido anuncio griego de celebrar un referéndum en torno a las condiciones de un segundo rescate, de modo que (y al margen del desplazamiento de buena parte de su agenda de discusión): mientras que Francia, Alemania y la misma Comisión invitaban a Grecia a olvidar el referéndum, el resto de potencias económicas observaban atónitas la inhabilidad europea para resolver definitivamente la crisis griega; una crisis que, a su vez, se extendía al resto de Europa, para alcanzar luego cierto remanso tras el comentado Consejo Europeo de 8 y 9 de diciembre de 2011; pero mero remanso, al fin y al cabo, tras las también comentadas elecciones griegas de mayo de 2012, la ulterior incapacidad de formar gobierno (entonces), una nueva convocatoria electoral para el 17 de junio, y el temor de que, a la vista de aquéllas, Grecia se opusiera definitivamente a las condiciones de su rescate, con el riesgo de que finalmente ésta saliera del euro (arrastrando, potencialmente, las economías del resto de la zona euro, del resto de Europa, como del resto del mundo), sin perjuicio del alivio que ha supuesto, por ahora, tales resultados electorales a la vista del acuerdo de gobierno alcanzado a favor del rescate (mas planteando su renegociación).

114 Vid. Vecchio, F., Primato del diritto europeo e identità costituzionali, Bonanno Editore, Acireale, 2011; y «Primacía del derecho europeo y contralímites como técnicas para la relación entre ordenamientos», Revista de Derecho Constitucional Europeo, núm. 17, 2012, http://www.ugr.es/ redce/REDCE17/articulos/02 VECCHIO.htm (27/07/2012).

${ }^{115}$ Así, ya, Balaguer Callejón, F., «La constitucionalización de la Unión Europea y la articulación de los ordenamientos europeo y estatal», en AAVV El constitucionalismo en la crisis del Estado social, García Herrera, M.A. (dir.), Universidad del País Basco, 1997, pp. 593 y ss.

${ }_{116}$ Al respecto, vid. ElíAs MéndeZ, C., «La jurisdicción constitucional en los Estados miembros de la Unión Europea», Revista de Derecho Constitucional Europeo, núm. 16, 2011, en http:/www.ugr.es/ redce/REDCE16/articulos/01CElias.htm (27/6/2012). 
Y en cuanto a la crisis española (y paralelamente a lo recién referido), se advierte la extensión del aforismo de a quién llamar por teléfono en Europa (KISSINGER) ${ }^{117}$ al interno ahora de la propia Unión: las diversas posturas mostradas por las instituciones europeas (en especial la Comisión y el Banco Central Europeo), además de Francia y Alemania, en torno a la vigente crisis española, y las distintas solicitudes de ayudas desplegadas por el Gobierno de España a fin de contener la presión sobre la deuda soberana española (llegando incluso al Fondo Monetario Internacional y a la Administración norteamericana), son muestra de cómo un problema que amenaza de manera crítica toda la zona euro (e incluso, a nivel internacional) no encontraba ni una única respuesta, ni un único interlocutor.

$\mathrm{Y}$ es que los presupuestos sobre los que se fundamentan el gobierno de Europa (equilibrio institucional, a nivel interno, junto a integración y cooperación, en relación a los Estados) terminan por palidecer, a nivel político, cuando surgen graves problemas y el conflicto, connatural al pluralismo, aflora; la cuestión no es sólo ya qué se decida, sino también quién y cómo, pues lo cierto es que el reparto vertical y horizontal del poder en Europa parece responder en la actualidad más a una hidra de múltiples cabezas, que a un modelo adecuadamente articulado, diferenciado, eficiente y colaborativo del poder. Por tanto, resulta necesario un fortalecimiento de una mayor unidad de acción en el gobierno europeo, que permita respuestas políticas y jurídicas eficientes, efectivas y expeditas ante la realidad cambiante que supone la globalización, en general, y la crisis, en particular $^{118}$. Mas ello, sin perjuicio de reconocer que tal fortalecimiento y profundización de la gobernanza europea ha de suponer mayor integración y trasferencia de soberanía de los Estados a la Unión, y con esto mayores dosis de constitucionalización y democratización de Europa, pues sólo la intensificación constitucional y democrática de ésta podría compensar dicha trasferencia en relación a las Constituciones nacionales ${ }^{119}$.

$\mathrm{Y}$ en cuanto a la pérdida de poder público a nivel Europeo y estatal, bien puede esgrimirse, con todo, que el nivel constitucional en Europa ha

${ }^{117} \mathrm{Al}$ respecto de este aforismo, vid. Meunier, S. y NicolaïDIs, K., «Who Speaks for Europe? The Delegation of Trade Authority in the European Union», Journal of Common Market Studies, núm. 37/ 3, 1999, p. 478.

${ }^{118}$ Así, en torno a las carencias del sistema de gobierno en Europa tras el Tratado de Lisboa, Porras RAMíreZ, J. M., «La arquitectura institucional de la Unión Europea: consideraciones críticas tras su reforma en el Tratado de Lisboa», Revista de Estudios Políticos, núm. 156, 2012, en especial pp. 164 a 165.

${ }^{119}$ De alguna forma la muy criticada Sentencia Lisboa del Tribunal Constitucional alemán, de 30 de junio de 2009 (en atención a la lectura más restrictiva que ésta supone para el proceso de integración de Alemania en Europa; así por ejemplo, y entre otros muchos, HÄBERLE, P., «La regresiva 'Sentencia Lisboa' como 'Maastricht-II' anquilosada», BALAGUer Callejón, F. -trad.-, Revista de Derecho Constitucional Europeo, núm. 12, 2009, pp. 397 y ss.), bien puede suponer, en contrapartida, un impulso a una mayor constitucionalización europea, dado que sólo mayores dosis de democracia y garantía de los derechos 
crecido, pero no se ha conseguido constituir suficiente poder en ésta como para interactuar en relación al resto del mundo, como respecto a los mismos Estados miembros tanto a la hora de imponer medidas, como a la hora de garantizar una auténtica solidaridad interestatal. Es así que, y al momento de la crisis de la deuda soberana que se vive aun en la zona euro, ni la Unión, ni los Estados, posean instrumentos suficientes y adecuados como para solventar efectivamente la situación en la que nos encontramos. Tal vez, nuevamente, lo que ha pasado es que nos hemos olvidado de una base preexistente al momento de aprobarse el artículo 16 de la Declaración de los Derechos del Hombre y del Ciudadanos tras la Revolución Francesa (1789): que la limitación del poder ha de presuponer un poder efectivo y considerable a limitar ${ }^{120}$. Ciertamente, la progresión constitucional en Europa y Occidente, y a pesar de las amargas crisis vividas, consiguió poner al Estado al servicio efectivo de las personas mediante el principio democrático, el reconocimiento y garantía de los derechos fundamentales, y el desarrollo de un modelo de protección y promoción social; en una palabra, se había conseguido domesticar constitucionalmente al Leviatán ${ }^{121}$. Sin embargo, y a la sombra de la globalización, este Leviatán domesticado se ha visto postergado por otras fuerzas ajenas al control democrático y jurídico constitucional; fuerzas que, sin embargo, han asumido parte del poder que ha escapado de los Estados una vez que han visto limitado su poder por y para las personas tanto a nivel nacional, como en el proceso de integración europea. Y ello, además, a la sombra de un sistema económico internacional marcado por la desregulación que, sin perjuicio de entrar en crisis, ostenta con todo la pretensión de determinar la agenda política de poderes públicos y democráticos ${ }^{122}$.

fundamentales en la Unión podría permitir mayores cesiones de soberanía nacional (en cierto sentido, la lectura más optimista de CANTARO, A. en «Democracia e identidad constitucional después de la 'Lissabon Urteil'. La integración “protegida"», V, Faggiani -trad.asimismo en Revista de Derecho Constitucional Europeo, núm. 13, 2010, pp. 161 y 162).

${ }^{120} \mathrm{Al}$ respecto, García Herrera, M. A., «Vigencia de la Declaración de Derechos del Hombre y del Ciudadano: democracia e igualdad», en AAVV Derechos humanos y Revolución francesa, Letamendía Belzunde, F. y García Herrera, M. A. (coord.), Universidad del País Vasco, Bilbao, 1991, pp. 9 y ss.

${ }^{121}$ Sobre tal proceso, nuevamente GARCÍA Herrera, M. A. pero ahora «Poder judicial y Estado social: legalidad y resistencia constitucional», en AAVV Corrupción y Estado de Derecho: el papel de la jurisdicción, Perfecto Andrés IBÁÑEZ (coord.), Trotta, Madrid, 1996, pp. 59 y ss. Asimismo, de interés, vid. Racionero Carmona, F., Antileviatán: la cultura de los Derechos, Dykinson, Madrid, 2003.

${ }^{122} \mathrm{De}$ alguna forma, es como el principio de «conservación de la energía», pero ahora en relación al poder en cuanto que éste no desaparece, sino que se transforma, desplazándose a espacios menos controlados. Y de este modo que, con SALVADORI, M. quepa hablar de una oligarquía financiera controlando la democracia, y vaciándola así de contenido, en Democrazie senza democracia, Editori Laterza, Roma-Bari, 2011. 


\section{CONSIDERACIONES FINALES: QUÉ HACER; DE VUELTA A LA CONSTITUCIÓN EUROPEA}

Sin duda, la limitación constitucional horizontal y vertical del poder en la Unión Europea ha progresado tanto como para afirmar una auténtica garantía multinivel de los ciudadanos frente al poder público ${ }^{123}$, aunque no en el mismo grado su legitimación y control democrático ${ }^{124}$; e incluso, podemos afirma un efectivo constitucionalismo cooperativo entre la Unión y los Estados miembros, si bien incapaz en la actualidad de dar respuesta a la crisis en la que se encuentra una y otros, a la vista de la debilitación de la normatividad de las Constituciones nacionales y sin la contraprestación de una verdadera Constitución europea (según se ha señalado más arriba), atenuado así la capacidad de los poderes públicos europeos (tanto estatales, como de la propia 5. Más bien, estamos en presencia de una constante búsqueda de instrumentos con los que mandar mensajes a un mercado financiero global, en vez de (intentar, al menos) articular auténticos mecanismos de control político y jurídico sobre el mismo.

Es por tanto que, sin perjuicio de no descuidar en ningún modo los niveles democráticos, jurídicos y sociales sobre los que se ha construido Europa ${ }^{126}$, se debiera volver a reconstituir el poder, si bien: de un lado, procurando recuperar parte del poder perdido hasta ahora, para así reintegrarlo en el espacio público y democrático europeo; de otro, articulándolo de manera tal que alcance un gobierno democrático, adecuado y efectivo de una Europa plural y social, a la par que lo suficientemente expeditivo en su capacidad de decisión; y siempre, eso sí, garantizando no obstante un espacio a favor de los Estados, a la par que se ar-

${ }^{123}$ Entre otros: Balaguer CAllejón, F., «Niveles y técnicas internacionales e internas de realización de los derechos en Europa. Una perspectiva constitucional», Revista de Derecho Constitucional Europeo, núm. 1, 2004, pp. 25 y ss.; BILANCIA, P. «Las nuevas fronteras de la protección multinivel de los derechos», asimismo en Revista de Derecho Constitucional Europeo, pero ahora núm. 6, 2006, pp. 255 y ss.; o SCHILlACI, A. «Los derechos fundamentales en la interacción constitucional europea», RAGONE, S. (trad.), también en Revista de Derecho Constitucional Europeo, núm. 17, 2012, http://www.ugr.es/ redce/REDCE17/articulos/01_SCHILLACI.htm (27/07/2012).

${ }^{124}$ Así, RidOLA, P., «La parlamentarización de las estructuras institucionales de la Unión Europea entre democracia representativa y democracia participativa», SÁNCHEZ BARRILAO, J. F. (trad.), Revista de Derecho Constitucional Europeo, núm. 3, 2005, 21 y ss.

${ }^{125}$ Sobre el constitucionalismo cooperativo, y siguiendo en gran medida a HäBERLE (mas advirtiendo los déficits de tal concepción respecto a la globalización): DE JuLIOSCampuzano, A., La transición paradigmática de la Teoría Jurídica (El Derecho ante la globalización), Dykinson, Madrid, 2009, pp. 215 y ss. (en particular, pp. 222-224); y nuevamente Ridola, P. pero ahora «Profilo storico del costituzionalismo moderno», en Diritto comparato e diritto costituzionale europeo, Giappichelli Editore G., Torino, 2010, pp. 25 y ss. (especialmente, p. 28).

${ }^{126}$ Sobre la necesidad de reforzar social y democráticamente Europa, vid. BALAGUER CALlejón, F., «Derecho y Justicia en el ordenamiento constitucional europeo», Revista de Derecho Constitucional Europeo, núm. 16, 2011, en http://www.ugr.es/ redce/REDCE 16/articulos/07FBalaguer.htm (27/6/2012). 
ticula una auténtica solidaridad entre los mismos (una Europa federal) ${ }^{127}$. Se respondería, de este modo, a las funciones básicas a las que ha de tender toda Constitución (seguridad, justicia y legitimidad, según PECES BARBA) ${ }^{128}$, y que hoy, en especial ante la crisis que vive Europa, no cabe apreciarse; y naturalmente, ello, desde una auténtica Constitución normativa europea, pues sólo con tal normatividad se podrá garantizar tanto la legitimidad democrática y pluralista del poder y su necesaria limitación (para que éste no sea omnímodo), a la par que un suficiente grado de densidad y cohesión del mismo como para que sea efectivo tanto a nivel interno de la Unión, como en relación a su acción exterior ante el resto de potencias, vigentes y emergentes (con unas BRICS, ahora, cada vez en mayor grado de cooperación), y frente al mercado en el actual contexto globalizado.

Cierto que una auténtica Constitución europea no dará satisfacción, por sí, a los retos que en relación a la globalización se viene de tiempo advirtiendo (como riesgos globales y control del desarrollo tecnológico, terrorismo y criminalidad globalizada, nuevos flujos migratorios y mayor desigualdad, el control del mercado y la especulación, o medio ambiente y cambio climático), al requerir respuestas globales y por tanto más allá de Europa; pero sí que potenciaría una mejor posición de ésta a la hora de articularse dichas respuestas a nivel internacional (global). Y tampoco, ciertamente, una Constitución europea garantiza una solución a la crisis de Europa, y en particular respecto a la deuda soberana en la zona euro, pero sí permitiría poseer mejores instrumentos políticos, jurídicos, financieros y económicos para atajarlas (y en su caso, evitarlas en el futuro), ante la limitación en la que hoy se mueven tanto los Estados, como la propia Unión.

Cierto es, asimismo, que diversos presupuestos clásicos para una Constitución en Europa siguen sin darse, como sería la existencia de un pueblo, y que la crisis está fomentando en diversos Estados una reacción frente a otros; mas, la necesaria solidaridad reclamada (en cuanto que auténtico deber jurídico y político, y no mera expresión de un voluntarismo pendiente de la oportunidad política) ${ }^{129}$ bien puede ser motor, si no de un pueblo europeo, sí que

${ }^{127}$ Parecer contrario, en cambio, en Habermas, J.; Bofinger P. y NidA-RÜmelin, J., «Por un cambio de rumbo en la política europea», Alborés Rey, J. (trad.), El País, 12 de agosto de 2012 (en http://internacional.elpais.com/internacional/2012/08/10/ actualidad/1344624171_292393.html -12/08/2012-), a pesar de reclamar una mayor profundización constitucional (a nivel institucional y democrática) de Europa, ante la situación de extrema gravedad que de la crisis se advierte en el verano de 2012: «El Estado federal es un modelo erróneo y excede el grado de solidaridad admisible por pueblos europeos históricamente independientes».

${ }^{128}$ Peces BARBA, G., «Las funciones de la Constitución», en AAVV Ciudadanía y Derecho en la era de la globalización, DE Julios-CAMPUZANO, A. (ed.), Junta de Andalucía/Dykinson, Madrid, 2007, pp. 51 y ss.

${ }^{129}$ Sobre tal entendimiento de la solidaridad, por todos, DE LUCAS, J., «La polémica sobre los deberes de solidaridad», Revista del Centro de Estudios Constitucionales, núm. 19,1994, pp. 10 y ss. 
de una mayor interrelación entre ciudadanos de diversos Estados, a la par que la crisis potencia, cada vez más, un espacio europeo de opinión pública y debate político ${ }^{130}$; nunca Europa ha estado tan pendiente de elecciones nacionales como hasta ahora (como las francesas o las griegas de mayo y junio de 2012), dada su ulterior repercusión para el resto de la Unión (también, las elecciones italianas y alemanas, previstas para 2013). Y cierto es, por último, que está por ver cómo pudiera ser tal constitucionalización final de Europa y en qué grado y extensión geográfica, de manera que quepa sospechar diversos niveles de constitucionalización en la Unión (como de hecho ya sucede en razón a la pertenencia, o no, a la zona euro), a la par que no cabe soslayar la dificultad misma de dicho proceso constitucional ante las reticencias ya manifestadas al respecto (recuérdese el fracaso del Tratado constitucional ${ }^{131}, \mathrm{y}$ el ulterior Tratado de Lisboa como respuesta $\left.{ }^{132}\right)^{133}$, y el riesgo de colapso que supone todo proceso constitucional ante su necesaria reforma (y es que tal hipotético proceso constituyente lo sería realmente de reforma, por cuanto que se partiría del estadio constitucional actualmente dado y de la relación y equilibrios de poderes ya existentes en Europa, de forma que dicho proceso constituyente/reformador supondría una restructuración de tales relaciones y equilibrios, y de ahí, consiguientemente, las reticencias de unos frente a otros) $)^{134}$.

Pero es que el abismo es excesivamente poderoso, y la amenaza de su arribada para Europa es tan evidente que no nos permite especular con un silencio de la Unión que la arrastre definitivamente al vacío. Lo que se plantea no es ya el progreso de la integración, sino su misma subsistencia ${ }^{135}$; una sub-

${ }^{130}$ Acerca de dicho espacio, vid. BosetTI, G., «Esiste un'opinione pubblica europea?», y OfFE, C. «Esiste, o può esistere, una "societá europea"?», GIALDRONI, A. (trad.), ambos en AAVV Sfera pubblica e costituzione europea?, Carocci Editore, Roma, 2002, pp. 49 y ss, y 95 y ss. (respectivamente).

${ }^{131}$ HÄBERLE, P., «Consecuencias jurídicas y políticas del doble 'no' francés y holandés a la Constitución Europea», FuENTES Osorio, J. (trad.), Revista de Derecho Constitucional Europeo, núm. 4, 2005, pp. 431 y ss.

${ }^{132}$ Nuevamente HäBERLE, P. pero ahora «El Tratado de Reforma de Lisboa de 2007», Balaguer Callejón, F. (trad.), también en Revista de Derecho Constitucional Europeo, núm. 9, 2008, pp. 11 y ss.

${ }^{133}$ En torno al debate sobre la ratificación prevista para tal Tratado, y sus propósitos y dificultades, vid. LóPez CASTILlo, A., «A propósito del proceso de ratificación del Tratado Constitucional de la Unión Europea», en AAVV La Constitución de la Unión Europea, Closa Montero, C. y Fernández Sola, N. (Coord.), Centro de Estudios Políticos y Constitucionales, Madrid, 2005, pp. 165.

${ }^{134}$ Sobre las paradojas que supone la necesidad de reforma constitucional, por todos, ZAGREBELSKY, G., «I paradossi della riforma costituzionale», en AAVV Il futuro della costituzione... cit., pp. 293 y ss.

${ }^{135}$ No en vano, una hipotética salida del euro de Grecia (lo cual se postula al momento de escribir estas páginas -25/05/2012-), arrastraría muy posiblemente a otros Estados ya intervenidos, como Irlanda, Portugal y España, o en graves dificultades económicas, como 
sistencia, por su parte, condicionada a una efectiva profundización política, democrática, jurídica, social y económica articulada mediante una Constitución normativa que garantice dicha integración, como la posición de los Estados (aun disminuida) y la de los ciudadanos, como fundamento último de ésta, a la par que garante de un diseño del ejercicio de poder capaz de actuar lo suficientemente rápido como para satisfacer el interés general y unitario de la Unión, como el plural de los Estados y de los pueblos que integran la Unión, ante una realidad cambiante y exigente de expeditivas respuestas. Y en tal sentido que nos volvamos a plantear, además, la necesidad de una racionalización del sistema político en Europa (cómo no, B. Mirkine-GuETZÉVITCH) ${ }^{136}$, ante el riesgo, si no de vacío del poder político ${ }^{137}$, sí que de inoperancia e ineficacia del mismo; una racionalización, entiendo, que ha de suponer una mayor y efectiva capacidad de decisión a nivel europeo frente a ésta (y otras y futuras crisis), mediante instrumentos y recursos propios de la Unión, a la par que más solidarios con los Estados y los ciudadanos que la integran ${ }^{138}$.

Italia y Bélgica, lo que finalmente pondría en jaque mate no sólo la aventura del euro, sino la misma integración europea. No obstante, también cabría plantearse una otra configuración del euro, en torno a Alemania y otras economías del norte que aún se mantienen fuertes (y una vez excluidas las economías periféricas, más débiles); mas ello, claro está, si es que dichas economías pudieran efectivamente mantenerse ante un mercado ahora más limitado. También, para este último caso, habría que plantearse si tiene entonces sentido permanecer en Europa; del ¡más Europa!, se estaría pasado al ¿más Europa?

${ }_{136}$ Mirkine-Guetzevitch, B., Modernas tendencias del derecho constitucional, ÁLvarez Gendin, S. (trad.), Editorial Reus, Madrid, 1934.

${ }^{137}$ Como el que ha planeado en Grecia tras las elecciones de mayo, la incapacidad política de formar gobierno, la convocatoria de nuevas elecciones en junio y el riesgo de unos nuevos resultados electorales que reproduzcan una falta de mayorías suficientes, sin perjuicio de que, tras las referidas elecciones de 17 de junio de 2012, finalmente se haya alcanzado un gobierno de coalición (según se viene indicando).

${ }^{138} \mathrm{Al}$ respecto, sin duda, la justificación que presenta HAMiLTON, A. respecto a los impuestos federales desde el principio de solidaridad, y en relación a una «Defensa común», junto a Madison, J. y JAY, J. en El federalista, Velasco, G.R. (trad.), Fondo de Cultura Económica, México, 1943 (5 reimp., 1994), pp. 96 y ss. Desde luego, lo que no cabe es solidaridad a cambio de soberanía, sin más (la solidaridad tiene un precio): lo que la solidaridad ha de suponer es una mayor responsabilidad ante Europa (y a nivel interno-nacional, en especial de aquéllos que han originado la situación de necesidad, en su caso), pero no la excusa (sobre todo, al tener que ser solicitados los mecanismos de solidaridad, ahora) para una reducción de la soberanía de un Estado sin el consiguiente traspaso democrático a la Unión; y es que tal aproximación a la solidaridad nos recuerda más a un añejo concepto de «caridad», en el que quien necesita se ha de humillar pidiendo, y el que da, desde la superioridad que le supone el poder dar, determina a aquél cómo y en qué se lo ha de gastar. Al contrario, la solidaridad es un principio que ha de actuar de manera cuasi-automática, de forma que ante la necesidad de uno, el grupo actúe rápidamente no sólo en interés de aquél, sino del propio grupo en su conjunto. De este modo la solidaridad no sólo refuerza la idea de integración (en su sentido más smendiano), sino también la percepción que desde 
Sin duda, el abismo ante el que se encuentra la Unión Europea evidencia la excepcionalidad y la inmediatez de las respuestas ${ }^{139}$, lo que sin embargo dificulta entablar un proceso de reforma pausado de los Tratados constitutivos; y de ahí, claro está, que entendamos justificados réplicas que, sin obviar a medio plazo dichas reformas (y paralelamente) ${ }^{140}$, procedan a buscar medidas más aceleradas destinadas a salvar Europa de la crisis (o al menos, contenerla). En tal contexto entendemos la viabilidad de respuestas como el Tratado de Estabilidad, Coordinación y Gobernanza en la Unión Económica y Monetaria (los referidos Consejos Europeos de 8 y 9 de diciembre de 2011, y de 30 de enero de 2012), pues aunque limitado a reforzar la integración interestatal en relación a la disciplina presupuestaria, y sin progresar en una auténtica integración política, democrática y solidaria (lo que no compartimos), procuran una respuesta plausiblemente más rápida a la vista de su procedimiento de ratificación y entrada en vigor (art. 14) ${ }^{141}$; otra cosa es, claro está, si la mayor rapidez de dichos mecanismos es suficiente ante la inmediatez de la exigencia de respuestas que cabe hoy apreciar ante la crisis, y por tanto, y por qué no, la hipótesis de otros instrumentos a modo de un Derecho de excepción europeo ante la situación de emergencia en la que se encuentra tanto la Unión, como algunos de sus Estados ante la dificultad de acudir a los mercados internacionales a fin de conseguir financiación, y el riesgo cierto que ello conlleva para todos en relación a la pervivencia de los presupuestos jurídicos y políticos que los identifican como sistemas democráticos y de Derecho ${ }^{142}$.

fuera se tenga sobre la cohesión y la fuerza del grupo (de la Unión); esto sí que es, a nuestro entender, un buen mensaje a mandar a los mercados, y no el espectáculo de debates sin respuestas claras, mientras la situación de necesidad de alguno se agrava.

${ }^{139}$ A fecha de 12 de junio de 2012, la Directora del Fondo Monetario Internacional, en una entrevista a la cadena $\mathrm{CNN}$, hablaba de un plazo de 3 meses en relación a la toma de medidas respecto a la zona euro; en http://economia.elpais.com/economia/2012/06/12/actualidad/1339470968_711061.html (13/06/2012).

${ }^{140}$ Es así que el fiñ de una definitiva integración constitucional de Europa a largo plazo nos resulte excesivo, por cuanto que la aceleración de los tiempos que marca la globalización impide seguir postergándola. Es demasiado el tiempo que se ha perdido en estos años; un tiempo, por tanto, del que ya no disponemos.

${ }^{141} \mathrm{Al}$ respecto, vid. CLOSA, C. «Jugando a ratificar: las reglas de entrada en vigor del nuevo Tratado de Estabilidad, Coordinación y Gobernanza del euro», Real Instituto Elcano, ARI 15/2012-7/03/2012, en http://www.realinstitutoelcano.org/wps/portal/rielcano/contenido?WCM GLOBAL CONTEXT=/elcano/elcano es/zonas es/organismos+internacio-

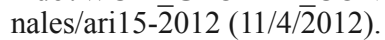

${ }^{142}$ Como de hecho ya ha acontecido en relación a la compra por el Banco Central Europeo de deuda de Estados miembros, aun en el mercado secundario, a fin de rebajar la prima de riesgo de éstos y facilitar la capacidad de los mismos para su financiación crediticia durante el mes de agosto de 2011 (sin perjuicio, luego, de su negativa a tal compra ya en verano de 2012, y las graves dificultades de España e Italia para financiarse en los mercados, pareciendo abocarlos así a un rescate imposible). No en vano, si tradicionalmente 
Para finalizar, una solución, la de una Constitución en ultima instancia para la Unión Europea (¡más Europa!), que supone volver a la historia misma del desarrollo constitucional en Europa ${ }^{143}$, pero más allá, eso sí, de su identificación estatal, para progresar en su articulación social, democrática y federal en la Unión ${ }^{144}$. Sólo a partir de ahí cabría ahora postular nuevas perspectivas en relación a cómo solventar los déficits y retos ante los que se encuentra el constitucionalismo ante la globalización desde Europa ${ }^{145}$. Lo demás sería rendirnos a una realidad que norma (en vez de normar la realidad), y volver a estadios constitucionales pasados, limitándose a un constitucionalismo débil y oligárquico; un constitucionalismo que a nivel de Europa supondría un Derecho constitucional europeo al servicio de unos frente a otros, y del mercado ante las personas, en vez de garantía del pluralismo y cauce pacificador del consiguiente conflicto; y una constitucionalización que, aunque reconocible al día de hoy (finalmente), se muestra inoperante ante la crisis y la globalización, y por tanto en decadencia (¿más Europa... ?; y entonces, ¿para qué y quiénes?).

el Derecho de excepción se ha planteado, en el marco del constitucionalismo, en relación al mantenimiento del sistema político y de la normalidad constitucional ante riesgos naturales y ataques a la seguridad pública y la defensa nacional, no habría que descartar el riesgo que para tal normalidad constitucional y los derechos de las personas supone ciertas situaciones de gravísimas crisis económicas (como la que vivimos), en las que se llega a plantear la pervivencia del modelo político, jurídico, social y económico. Ya, sobre la necesidad de reflexionar sobre un Derecho de excepción a nivel europeo, vid. FAGGIANI, V. «Los estados de excepción. Perspectivas desde el derecho constitucional europeo», Revista de Derecho Constitucional Europeo, núm. 17, 2012, http://www.ugr.es/ redce/RED CE17/articulos/05 FAGGIANI.htm (27/07/2012).

${ }^{143}$ Cómo no, sobre tal tradición, FioravanTI, M., Constitución (De la antigüedad a nuestros dias), MARTínez NeIRA, M. (trad.), Trotta, Madrid, 2001, pp. 142 y ss.

${ }^{144}$ Ya, Morelli, U., «La Constitución europea. El modelo federalista», CuAUTLE RodríGUEz, E. (trad.), Boletín Mexicano de Derecho Comparado, núm. 117, 2006, pp. 723 y ss.

${ }^{145}$ Nuevas perspectivas que, conforme se indicó anteriormente, requieren también de reformas constitucionales en el seno de los Estados miembros, peo no ya simplemente para solventar inconstitucionalidades inmediatas entre los Tratados originarios de Europa y las respectivas Constituciones, sino desde una visión políticamente más global en relación a las mismas Constituciones nacionales, en su conjunto, como en relación al proceso de integración europea. 